\title{
Environmentally Benign Tribo-systems for Metal Forming Keynote paper
}

Bay, Niels; Azushima, A.; Groche, P.; Ishibashi, I.; Merklein, M.; Morishita, H.; Nakamura, T.; Schmid, S.; Yoshida, $M$.

\section{Published in:}

C I R P Annals

Link to article, DOI:

10.1016/j.cirp.2010.05.007

Publication date:

2010

Link back to DTU Orbit

Citation (APA):

Bay, N., Azushima, A., Groche, P., Ishibashi, I., Merklein, M., Morishita, H., Nakamura, T., Schmid, S., \& Yoshida, M. (2010). Environmentally Benign Tribo-systems for Metal Forming: Keynote paper. $C I R P$ Annals, 59(2), 760-780. https://doi.org/10.1016/j.cirp.2010.05.007

\section{General rights}

Copyright and moral rights for the publications made accessible in the public portal are retained by the authors and/or other copyright owners and it is a condition of accessing publications that users recognise and abide by the legal requirements associated with these rights.

- Users may download and print one copy of any publication from the public portal for the purpose of private study or research.

- You may not further distribute the material or use it for any profit-making activity or commercial gain

- You may freely distribute the URL identifying the publication in the public portal 


\section{Elsevier Editorial System(tm) for CIRP Annals - Manufacturing Technology}

Manuscript Draft

Manuscript Number: 2010-Keynote-FR2

Title: Environmentally Benign Tribo-systems for Metal Forming

Article Type: 2010 Volume 2 (Keynote paper)

Keywords: Metal forming tribology, Lubricants, Environmental impact, Tool materials, Tool coatings, Structured workpiece surfaces, Structured tool surfaces

Corresponding Author: Professor Niels Bay, MSc, PhD, DSc

Corresponding Author's Institution: Technical University of Denmark

First Author: Niels Bay, MSc, PhD, DSc

Order of Authors: Niels Bay, MSc, PhD, DSc; Niels Bay, Professor, MSc, PhD, DSc; Akira Azushima; Peter Groche; IItaru Ishibashi; Marion Merklein; Hirokazu Morishita; Tamotsu Nakamura; Steven Schmid; M. Yoshida

Manuscript Region of Origin: DENMARK

Abstract: The growing awareness of environmental issues and the requirements to establish solutions diminishing the impact on working environment as well as external environment has initiated ever increasing efforts to develop new, environmentally benign tribological systems for metal forming. The present paper gives an overview of these efforts substituting environmentally hazardous lubricants in cold, warm and hot forging as well as sheet forming and punching/blanking by new, less harmful lubricants and furthermore describes other more generic measures directed towards the same goal such as development of anti-seizure tool materials and coatings and application of structured workpiece and tool surfaces. 


\title{
Environmentally Benign Tribo-systems for Metal Forming
}

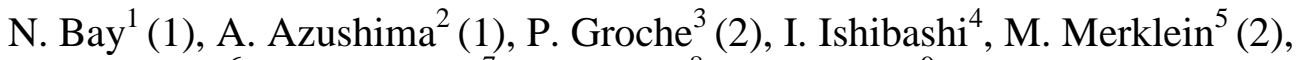 \\ M. Morishita ${ }^{6}$, T. Nakamura ${ }^{7}$, S. Schmid ${ }^{8}$, M. Yoshida ${ }^{9}$ \\ ${ }^{1}$ Department of Mechanical Engineering, Technical University of Denmark, Denmark \\ ${ }^{2}$ Department of Mechanical Engineering and Materials Science, Yokohama National University, Japan \\ ${ }^{3}$ Technical University of Darmstadt, Germany \\ ${ }^{4}$ Sumico Lubricants Co., Japan \\ ${ }^{5}$ Chair of Manufacturing Technology, University of Erlangen-Nuremberg, Germany \\ ${ }^{6}$ Toyota Motor Corp., Japan \\ ${ }^{7}$ Department of Mechanical Engineering, Shizuoka University, Japan \\ ${ }^{8}$ Department of Aero \& Mechanical Engineering, University of Notre Dame, USA \\ ${ }^{9}$ Nihon Parkerizing Co., Japan
}

\begin{abstract}
The growing awareness of environmental issues and the requirements to establish solutions diminishing the impact on working environment as well as external environment has initiated ever increasing efforts to develop new, environmentally benign tribological systems for metal forming. The present paper gives an overview of these efforts substituting environmentally hazardous lubricants in cold, warm and hot forging as well as sheet forming and punching/blanking by new, less harmful lubricants and furthermore describes other more generic measures directed towards the same goal such as development of anti-seizure tool materials and coatings and application of structured workpiece and tool surfaces.
\end{abstract}

Metal forming tribology, Lubricants, Environmental impact, Tool materials, Tool coatings, Structured workpiece surfaces, Structured tool surfaces

\section{Introduction}

Since 2000 legislation in Europe and Japan has been increasingly restrictive with respect to the industrial application of hazardous lubricants, [53,80,81] and in 2006-2007 the EU introduced new legislation, REACH, aiming at a high level of protection of human health and the environment from the risk posed by chemicals. REACH makes industry responsible for assessing and managing the risks posed by chemicals and providing appropriate safety information to their users. Due to these legislative initiatives, manufacturers are increasingly focused on environmental concerns and request their suppliers to act proactively to establish safe and healthy working conditions while limiting the strain on the environment. In the United States, exposure to harmful chemicals is regulated by the Occupational Safety and Health Administration and control of pollutants in wastewater or atmosphere exhaust by the Environmental Protection Agency. Proposed standards suggest limitation or elimination of certain carcinogenic chemicals commonly used in metalworking lubrication, [78].

Environmental problems in metal forming tribology, can be divided into the following areas, [89]: a) health and safety of people, b) influence on equipment and buildings, c) destruction and/or disposal of waste and remaining products. Improvement efforts are concentrated on 1) elimination of hazardous chemicals, e.g. chlorinated additives or phosphates with (heavy) metal sludge, and 2) reduction of waste, including prolonging tool and lubricant life, recovery and reuse of lubricants and Minimal Quantity Lubrication (MQL).

Regarding cold forging the substitution of zinc phosphating plus soap with environmentally benign lubrication systems is of interest due to sludge accumulation in the baths and its associated content of heavy metals, [90,138,147,154,218]. Regarding warm and hot forging, graphite based, "black" lubricants are being replaced by "white" lubricants due to bad working environment, leakage to soil and groundwater or pipe corrosion due to their electric conductive properties and low recovery rate due to their inferior oil separation, [138].

As regards sheet metal forming, chlorinated paraffin oils are often used in forming of materials prone to galling such as advanced high strength steels, stainless steel and titanium, as well as in tribologically demanding processes such as punching and ironing, and present a serious environmental concern. Significant research has been expended towards finding alternatives by combining new lubricants with anti-seizure tool materials and coatings, [25,90,115,147,202]. 
The present paper gives an overview of the development and testing of alternative, environmentally benign lubricants for cold forging, warm/hot forging, rolling, and sheet metal forming and punching/blanking. Furthermore, generic measures towards substitution of hazardous lubricants with alternative, more environmentally friendly ones are discussed. These measures include anti-seizure tool materials and coatings and application of structured workpiece and tool surfaces.

\section{Tribological loads in metal forming}

Suitable tribological systems for metal forming impede direct contact between tool and workpiece. By this separation reduced tool wear is achieved because the risk of adhesion is minimized. Additionally, in most cases friction forces are reduced.

Quality and type of lubrication which are required to realize tool workpiece separation and friction reduction depend strongly on the tribological loads that appear in a specific process. The tribological load can be mainly characterized by the following parameters: Contact normal stresses, surface enlargement, relative velocity between tool and workpiece as well as initial temperature. Fig. 1 shows characteristic loads for typical forming processes. Sometimes the sliding distance plays another important role for the design of a tribological system.

\begin{tabular}{|c|c|c|c|}
\hline \multirow{8}{*}{ 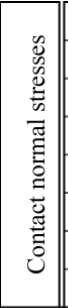 } & \multicolumn{3}{|l|}{ cold forging } \\
\hline & hot forging & & \\
\hline & deep drawing & & \\
\hline & ironing & & \\
\hline & hot sheet metal forming & & \\
\hline & cold rolling & & \\
\hline & hot rolling & & \\
\hline & punching and blanking & & \\
\hline $\begin{array}{c}\sigma_{\mathrm{N}} \\
{\left[\mathrm{N} / \mathrm{mm}^{2}\right]}\end{array}$ & $\begin{array}{ll}750 & 1,500 \\
\end{array}$ & 2,250 & $\frac{1}{3,000}$ \\
\hline
\end{tabular}

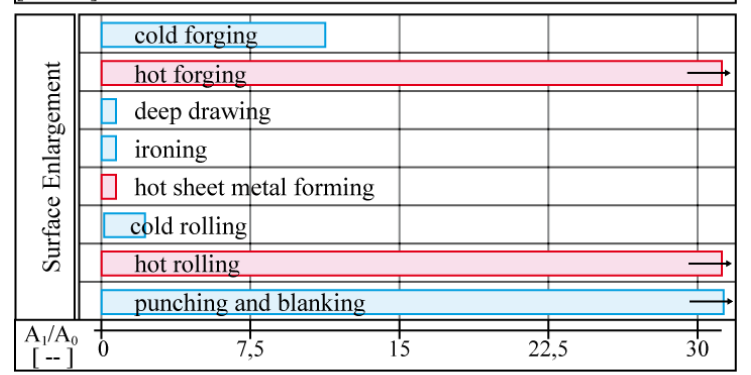

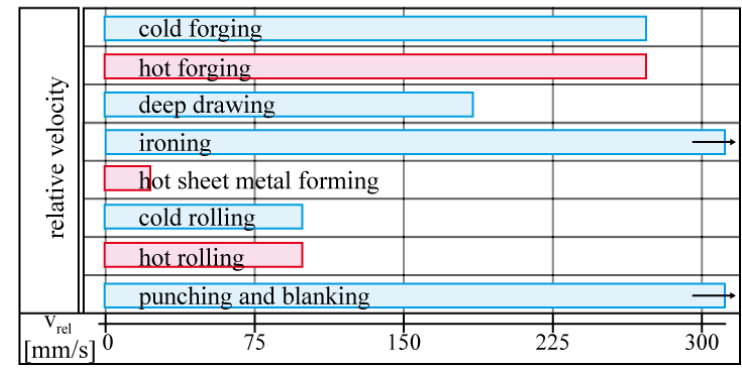

Fig. 1. Characteristic loads for typical tribological systems

The large range of loads illustrates the need for different special lubricants, anti wear coatings and additional tribological components like functional surfaces, to efficiently maximize tool life. Due to the fact, that tribological systems depend strongly on the kind of metal forming process, the structure of the following chapters follows the classification of forming processes.

\section{Cold forging}

Development of the cold forging process of steel and its successful application in the automotive industry since 1960 is closely connected to the development of efficient lubrication systems consisting of a conversion coating of zinc phosphate chemically bonded to the metal substrate. The coated part is provided with a lubricant by dipping into a hot bath of alkaline soap (typically sodium stearate) that reacts with the zinc phosphate to form zinc stearate, which is eventually covered with excessive sodium soap $[24,88]$. The crystalline layer of zinc phosphate partly acts as a chemical agent binding the soap to the surface, and partly as physical carrier for the soap. The coating procedure has several environmental drawbacks [48,59,147,183,186]: a) Sludge of (heavy) metal phosphates, which need to be reclaimed or buried, b) Large water requirement in the rinse baths, c) Periodic replacement of baths for degreasing, neutralizing, pickling and lubrication required, d) Large amounts of waste water, typically containing grease and tramp oils, acid, and soap. In addition to these environmental concerns, the phosphating process requires prolonged treatment time, typically 5-15 min. and high bath temperature, $80-90^{\circ} \mathrm{C}$, $[88,147]$.

Zwez and Holz, [221], report that modification of zinc phosphate coatings with calcium reduces the load of heavy metal zinc by $33 \%$ thus reducing the impact on environment. Within this conventional chemical treatment much progress has been made in the last decades to reduce the consumption of chemicals and the amount of waste water. The use of advanced products for cleaning, pickling, phosphating and lubrication as well as improved monitoring and adjustment of the chemical process prolongs the service life of baths considerably and reduces the consumption of chemicals by approximately $20 \%$. For drawing of wire, tubes and profiles as well as for cold heading phosphating agents with nitrite or chlorate as accelerator are still widely used. This so-called "iron-free" phosphating process results in huge amounts of sludge of iron and heavy metal phosphates, which has to be disposed by burying. By introducing new phosphating agents without the accelerating compounds of nitrite and chlorate, the consumption of phosphating agents can be reduced by one third and the amount of sludge by $80-90 \%$. Recent developments have led to new, advanced aqueous dispersions both of polymer lubricants and $\mathrm{MoS}_{2}$. The improved adhesion and increased forming capability allow a reduction of the number of complete chemical pre-treatment steps, e.g. lubrication without phosphating.

For less demanding cold forging operations such as bolt production, the soap is replaced by oil. Table 1 presents an overview of their major content [147,212]. The effects of sulphur and phosphorus based extreme pressure additives were intensively studied in the period 1986-1991 by Komatsuzaki $[119,120]$ et al. and Ohmori et al. [155,156]. As shown in Fig. 2 phosphate compounds assist lubrication at lower temperatures, sulphur compounds in a somewhat higher range, but none of them is effective in the intermediate range from $200-300^{\circ} \mathrm{C}$.

Adding phosphate compounds like alkyl acid phosphate to a lubricant formulated with sulfur additives feasible for high temperatures makes it possible to obtain stable lubrication in this medium temperature range, [147,212]. Attempts to add metallic compounds of $\mathrm{Ca}$ and $\mathrm{Zn}$ have also occurred, and a variety of non-chlorinated cold forging oils are commercially available $[9,73,217]$. 
Table 1

Oil lubricants for cold forging, [212].

\begin{tabular}{cc}
\hline Ingredient & Main compounds \\
\hline Base oil & Mineral oil, fat and oil, synthetic ester \\
Extreme pressure additives & Phosphorus, chlorine and sulfur \\
Oiliness improving agent & Fatty acid, higher alcohols \\
Solid lubricant & Graphite, $\mathrm{MoS}_{2}$, PTFE, metal soap etc. \\
\hline
\end{tabular}

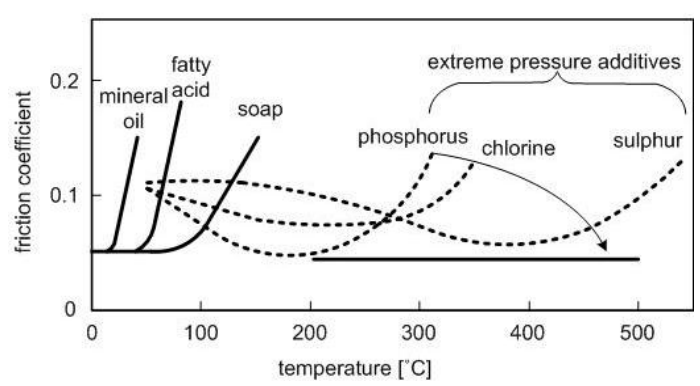

Fig. 2. Applicable temperature range of extreme pressure additives, $[178,212]$.

As alternatives to phosphate coating and soap, a number of lubrication systems for cold forging have been developed. They may be organized into the following groups:

- New conversion coatings

- Electrolytic phosphate coating

- Microporous coating

- Lubrication without conversion coating

- Dual bath systems

- Single bath systems

\subsection{New conversion coatings}

\subsubsection{Electrolytic phosphating}

Many of the drawbacks associated with zinc phosphates are eliminated by electrolytic phosphating, $[41,118,154]$. The main advantages are that a sludge free phosphating bath is obtained, the use of acid for pickling may be avoided by electrochemical pickling, the treatment time is considerably shortened, the working environment is improved and the electrochemical procedure makes it possible to phosphate high alloyed steels and stainless steel, as developed in the late 1990s by Bjerrum et al. [29,157]. Fig. 3 shows SEM micrographs of chemical phosphate coating and electrolytic phosphate coating. It can be seen that the e-phosphating ensures a much more uniform and finer crystalline coating with smaller film thickness. The phosphating time is $4 \mathrm{~s}$ for the electrochemical procedure compared to $5 \mathrm{~min}$. for the chemical procedure. Coating thickness can furthermore be much better controlled, since it is linearly related to current density and treatment time, [118]. Application of an electrolytical coating combined with zinc stearate as lubricant has demonstrated feasibility of severe cold forging operations such as backward can extrusion in AISI 304 stainless steel with reductions $r=$ $\left(D_{p} / D_{o}\right)^{2}=0.5$ and can heights $h=2 D_{p}$, [208].

Nittel [154] reports substitution of chemical zinc or zinccalcium phosphating with electrolytic calcium phosphating carried out at $25^{\circ} \mathrm{C}$ bath temperature. The process has the same

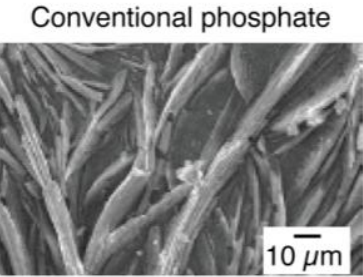

Electrolytic phosphate

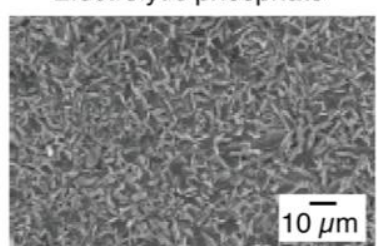

Fig. 3. SEM micrographs of conventional and electrolytic phosphate coatings, [118].

advantages as electrolytic zinc phosphating, i.e. (heavy) metal sludge in the phosphating bath is avoided. In fact, even the coating is free of heavy metals such as $\mathrm{Zn}$ and $\mathrm{Ni}$, and primarily consists of $\mathrm{CaHPO}_{4}$. It may be applied to highly alloyed steel and stainless steel and $\mathrm{Ti}$, although the latter has yet to be demonstrated. Due to energy savings (no heating of the phosphating bath) and in disposal of chemicals, the new conversion coating system also should have economic advantages. Lubricants may be similar to those applied to zinc phosphate coatings, i.e. mineral oil or metal stearate, but good results have also been obtained with polymer emulsions and dispersions consisting of polyamides, polyimides, polyurethanes and/or polyoelfines such as polyethylene and/or polypropylene, $[79,154]$. The film weight of the polymer lubricant is $1.5-2.5$ $\mathrm{g} / \mathrm{m}^{2}$ compared to $5-10 \mathrm{~g} / \mathrm{m}^{2}$ for soap, which leads to improved tolerances of cold forged components. The dust problems in wire drawing with soap lubrication are avoided and higher production speeds in bolt making machines are reported. Furthermore the problems of tramp oil (mixture of the process lubricant with the lubricating oil for the machinery) are avoided.

\subsubsection{Microporous coating}

Utsunomiya et al., [201], have developed a technique to produce porous surfaces in steel slugs by artificial oxidation at $600^{\circ} \mathrm{C}$ in air followed by subsequent reduction of the oxides in a hydrogen atmosphere at the same temperature. By this second treatment the oxide layer is transformed into a porous surface layer with an average pore diameter of app. $300 \mathrm{~nm}$. The thickness of this layer is about $1 \mu \mathrm{m}$. The porous structure is beneficial for entrapment of liquid lubricants, and ring tests of $0.15 \%$ C-steel (JIS S15CK) lubricated with machine oil with viscosity $32 \mathrm{cSt}$ at $40^{\circ} \mathrm{C}$ or grease gave friction almost as low as for phosphate coating plus soap lubrication.

Using a quite different technique Tang et al. [8,196] have also developed a porous coating that serves as an efficient lubricant carrier. A two-phase alloy of $\mathrm{Sn}$ and $\mathrm{Zn}$ is electrochemically deposited on the workpiece surface after which one of the two metals is selectively etched leaving a micro- or even nanoporous layer of the remaining metal on the workpiece surface, see Fig. 4. The layer thickness is typically $5 \mu \mathrm{m}$. When a lubricant subsequently is applied to the porous coating, it will be trapped in the pores acting as numerous small lubricant reservoirs and will be entrained in even the most demanding applications.
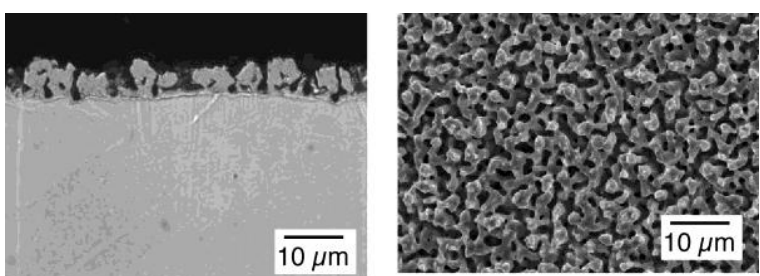

Fig. 4. Cross section and top view of new porous coating. 
Ring tests and double cup extrusion tests in St 1.0303 provided with the new lubricant carrier combined with plain mineral oil with no boundary lubricants and a viscosity of $60 \mathrm{cSt}$ at $40{ }^{\circ} \mathrm{C}$ produces friction as low as with phosphate coated and soap lubricated conditions. Single cup extrusion tests in the same material with high reduction $r=\left(D_{p} / D_{o}\right)^{2}=69 \%$ showed no lubricant film breakdown in cup extrusions up to cup heights $h=$ $2.7 D_{p}$.

\subsection{Lubrication without conversion coating}

\subsubsection{Dual bath systems}

Together with Sumico Lubricant, Nakamura et al. [148,149] have tested a number of alternatives including single as well as dual bath systems. The dual bath systems form a base coating adhering to the slug surface and an over-coating to further reduce friction. Two types of lubricants were investigated, a white lubricant consisting of wax and metal soap, and a black one consisting of $\mathrm{MoS}_{2}$ and graphite. Based on laboratory cold forging tests, two dual bath systems (with the two above mentioned lubricants) were selected for industrial testing in a multistage cold extrusion operation. Both systems showed good performance with no sign of pick-up on the tools.

\subsubsection{Single bath systems}

Lazzarotto et al. have tested commercial oils with extreme pressure additives for less demanding cold forward extrusion operations using an upsetting-sliding test showing the importance of the tool temperature as regards the limits of lubrication, [121]. In the case of more demanding cold forging operations, alternative single bath lubrication systems have been developed, especially in Japan. After descaling/shot blasting and hot water rinsing, the slugs are dipped in an aqueous bath containing inorganic salt and an organic lubricant and subsequently dried, after which they are ready for cold forging. The whole procedure takes about $2 \mathrm{~min}$. implying that in-process lubrication is attainable in many cold forging lines, [139,147].

Development of such lubricants was initiated by Toyota Motor Corp. together with MEC Int. Initial investigations were directed towards a series of different water based compounds with fatty acid, phosphates, polymer based dispersant and $\mathrm{Zn}$ and Mo-compounds [101,137,193]. In testing of the lubricants in backward can extrusion of $0.1 \%$ C-steel with a reduction $r=50 \%$ a can height $h=2.4 D_{p}$ were obtained without seizure. The research work resulted in the product MEC-HOMAT, a solid film lubricant applied by dipping in a water bath. During cold forging the heat developed by deformation and friction results in a chemical reaction between the steel slug surface and the lubricant film containing a chelating agent. The reaction generates iron sulphide and forms a boundary lubricating film with $\mathrm{Zn}$ and sulphur components, [147,200]. Moroi, et al. [139] report the lubricant to be industrially applied in a three stage cold forging production of a drive pinion shaft and a four stage production of a rear axle shaft. Surface expansion ratios of six and sliding lengths of $500 \mathrm{~mm}$ are successfully accommodated, i.e. conditions comparable to those applicable with conventional phosphate coatings and soap lubrication.

Daido Chemical Industry has developed Daido AquaLub [7] based on a phosphoric compound with adsorption ability onto metallic surfaces and solid lubricants. The generic chemical compositions are: a) calcium compound $5-10 \%$, b) water soluble inorganic salt $1-5 \%, c)$ phosphorous organic compound $0.5-1 \%$, d) lubricant surfactants $5-10 \%$, e) synthetic alcohol 5-10\%, f) water insoluble inorganic salts $5-10 \%$ and water $60-80 \%$. The application of this lubricant requires preparation of the billets by shot peening.

Ngaile et al. [152] describe the systematic development of new, environmentally friendly metal forming lubricants for steel based on co-polymer emulsions containing acrylic and methacrylic monomers. The polymer forms strong ionic bonds to the metal substrate. The procedure for coating includes alkaline cleaning, sulphuric acid pickling, conditioning, polymer coating with intermediate water between the operations and final drying in hot air. The conditioning provides the steel billets with an inorganic layer primarily consisting of iron phosphate and iron oxide. This layer ensures a greater quantity of polymer coating to be bonded in the subsequent step. Compared to conventional zinc phosphate coating and soap lubrication the treatment time is reduced by $25 \%$, the number of process steps are reduced from 9 to 7 and the water consumption is reduced by $75 \%$. Laboratory ring compression and twist compression tests of AISI 1018 workpieces with AISI D2 tool material proved low friction at room temperature as well as at $180^{\circ} \mathrm{C}$. Field trials in C-steel tube drawing showed good performance. The coating was capable of sustaining its lubrication layer even during multi-blow extrusion and multi-pass drawing.

Gariety et al. [58] have tested the performance of MECHOMAT lubricant as well as well as Daido AquaLub and compared their performance to conventional zinc phosphate coating and soap lubrication in cold forging of AISI 8610 steel using the double cup extrusion test. The friction factor obtained was lower for both of the two new, single-bath lubrication systems than for the zinc phosphate coating/soap system. Microscopic inspection of the upper cup inner surface showed no sign of lubricant failure. Common to the two new lubricant systems is that the lubricant is firmly bonded to the surface without creating hazardous chemical waste and with substantially reduced time for billet treatment. Groche and Koehler [66] have also tested a single bath lubricant including a compound of salt and wax. The workpiece material was $16 \mathrm{MnCrS5}$, which was shot blasted before extrusion in a 3-stage operation. Results showed the same low process force and ejector load as phosphate coating plus soap and good surface appearance.

Nihon Parkerizing has developed a single bath, water based lubricant for cold forging of steel, [218]. This product consists of an inorganic salt as base component and a wax as a lubricant. The application method is called "Dry-in-Place" and consists of a simple dip and dry process forming a double coating consisting of a lubricant carrier as base with a lubricant film on top. The base layer plays an important additional role in protecting against galling. The coating is claimed to be similar to the conventional triple layer coating formed by phosphating and soap lubrication. Comparison of the new coating with conventional phosphate coating and soap lubrication in backward can extrusion measuring the backstroke force has shown seizure occurring at larger can height with the new lubricant. Production trials show it to be applicable in almost the same range as phosphate coating and soap lubrication as seen in Fig. 5. The new lubricant has even been developed for cold forging of aluminium, where the requirements regarding surface expansion are much larger, [187].

The new, single bath lubricants are now applied in numerous cold forging operations at Toyota and under trial in the most complex ones. Substituting zinc phosphate coating plus soap with the new lubrication system has reduced the waste from former 360 tons to a present 45 tons, corresponding to $88 \%$ less waste. 


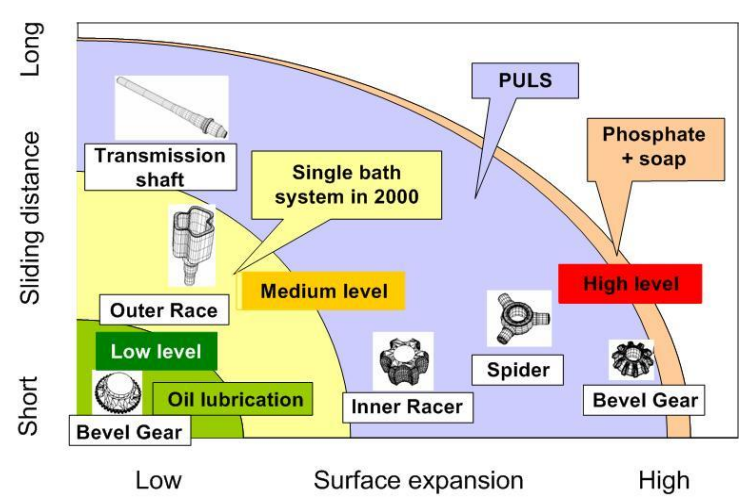

Fig. 5. Range of applicability of different cold forging lubricants, [187].

\section{Warm and hot forging}

In hot forging of C-steel, the workpiece is heated to 1000$1200^{\circ} \mathrm{C}$, but the die interface temperature has to be kept below $600^{\circ} \mathrm{C}$. This is achieved by spraying with lubricant containing a cooling medium or by using insulating films like glass and by keeping the contact time with the workpiece low. Since oxides themselves prevent seizure and reduce friction, many forging operations are done without lubrication. Low friction may furthermore not be desirable in hot forging, since this leads to increasing relative sliding between the workpiece and die which may cause increased wear, $[68,171]$. The role of the "lubricant" is then merely to ensure easy die release and saw dust has traditionally been used for this purpose. In complicated die forgings colloidal graphite dispersed in water or oil has been applied by spraying.

Table 2 shows traditional lubricants for hot forging of steel and a comparison of their properties [71]. Daouben et al. [42] have studied the influence of film thickness and particle size in graphite lubrication and propose an optimum lubricant film thickness to be $30 \mu \mathrm{m}$ in order to compromise between low tool wear and sufficient friction in the flash to ensure good form filling.

Table 2

Properties of lubricants for hot forging of steel.

1: Very good; 2. Good; 3. Satisfactory; 4. Poor; 5. Bad, [71].

\begin{tabular}{ccccc}
\hline Lubricant & $\begin{array}{c}\text { Sliding } \\
\text { friction }\end{array}$ & $\begin{array}{c}\text { Sticking } \\
\text { friction }\end{array}$ & $\begin{array}{c}\text { Gas } \\
\text { pressure }\end{array}$ & $\begin{array}{c}\text { Die } \\
\text { friction }\end{array}$ \\
\hline $\begin{array}{c}\text { Saw dust } \\
\text { 3.6\% colloidal }\end{array}$ & 4 & 4 & 1 & 1 \\
graphite in water & 1 & 1 & 5 & 5 \\
$\begin{array}{c}4 \% \text { colloidal } \\
\text { graphite in oil }\end{array}$ & 3 & 3 & 2 & 2 \\
$\begin{array}{c}\text { Polyalkaline } \\
\text { glycol }\end{array}$ & 5 & 5 & 4 & 4 \\
$\begin{array}{c}17 \% \mathrm{Na}_{2} \mathrm{CO}_{3} \\
\text { aqueous solution }\end{array}$ & 2 & 2 & 3 & 5 \\
\hline
\end{tabular}

Warm forging of steel is performed over a wide temperature range, $200^{\circ} \mathrm{C}-850^{\circ} \mathrm{C}$. This makes lubrication very difficult, since neither the lubricants for cold forging nor those for hot forging are fully effective. Table 3 shows guidelines for lubrication in warm forging over different temperature ranges, [71]. Efforts to find alternatives to graphite based lubricants have been driven by: a) Bad working environment, b) Earth leakage (electric
Table 3

Guidelines on lubricants for warm forging of steel, [71].

\begin{tabular}{|c|c|c|c|}
\hline $\begin{array}{c}\text { Temp. } \\
{\left[{ }^{\circ} \mathrm{C}\right]}\end{array}$ & Surface treatment & Lubricant & Application \\
\hline $\begin{array}{c}200- \\
400\end{array}$ & Phosphate coating ${ }^{1}$ & $\begin{array}{c}\text { Graphite } \\
\mathrm{MoS}_{2}\end{array}$ & Workpiece \\
\hline $\begin{array}{l}400- \\
700\end{array}$ & $\begin{array}{l}\text { Phosphate coating } 1 \\
\text { may be applied but } \\
\text { heating should be } \\
\text { fast }\end{array}$ & $\begin{array}{c}\text { Graphite } \\
\text { Graphite dispersed } \\
\text { in water }\end{array}$ & $\begin{array}{c}\text { Workpiece } \\
\text { or tool2 }\end{array}$ \\
\hline $\begin{array}{l}700- \\
850\end{array}$ & None & $\begin{array}{c}\text { Graphite } \\
\text { (rapid heating) } \\
\text { Graphite dispersed } \\
\text { in water }\end{array}$ & $\begin{array}{l}\text { Workpiece } \\
\text { and tool }\end{array}$ \\
\hline
\end{tabular}

${ }^{1}$ Phosphate coating cannot be used for high alloy steel and stainless steel. Instead either oxalate coating or plating may be applied.

${ }^{2}$ Lubrication of the tool surface only may be sufficient in upsetting and backward extrusion. Spraying is preferable as application method.

conductivity of oil), c) Pipe corrosion due to electric conductivity, d) Low recovery rate due to poor oil separation, [138].

In 1983 a water soluble, carboxylic acid based high molecular weight, short chained compound was developed as a first substitute to graphite based lubricants, [28]. This lubricant, which has good adherence to hot die surfaces at a temperature of $400^{\circ} \mathrm{C}$ and good lubricity were soon introduced in forging production of automotive parts and started the development of non-graphite based lubricants for warm and hot forging, [130]. From around 1985 a number of alternatives to the graphite based lubricants were actively promoted in industry.

Nakamura [146] gives a comprehensive overview of the lubricants applied for warm and hot forming of C-steels, high alloyed steels, Ni-alloys and Al-alloys. The lubricants include calcium stearate, water soluble high-molecular weight polymer, high-molecular weight carboxylate, water soluble glass, super high-molecular weight polyethylene, $\mathrm{BN}+$ glass + graphite, graphite $+\mathrm{B} 2 \mathrm{O} 3$, graphite + resin, etc. Kawabe [105] reports results of a Japanese industry survey in 1993 disclosing that $21 \%$ of the companies had totally abandoned graphite based lubricants and were exclusively using white lubricants, but die life was considerably lowered. Less than 10 years later, in 2001 white lubricants were narrowed down to the following [137,147]: 1) Polymer base, 2) Carvone base, 3) Liquid glass base.

Hibi [70] gives a good overview of possible water soluble high-molecular weight polymers for warm and hot forging. The main element in the polymer base is alkyl maleate. The carvone base oils are essential oils such as volatile or ethereal oils from plants. The main content of these lubricants are carboxylic acids such as fumaric acid and isophtalic acid. The liquid glass base lubricants are Si-glass containing colloidal silica.

Friction tests show dry films of high molecular weight polymer as well as graphite to give lower friction than wet films and the high molecular weight polymer providing a level of lubricity at least equivalent to that of graphite [216]. However, while a water-soluble white lubricant improves the working conditions compared to a graphite lubricant in general, it continuously dissolves in water, and produces a high environmental burden associated with difficulties in waste liquid disposal. Especially with recycled use, it is liable to deteriorate in cooling performance and lubricity due to mixing of sludge containing operating fluid for the press, oxidized scale, etc. 
Therefore, separation of such oil content and sludge and improvement in the disposability of waste liquid are the keys to improving environmental performance, [147]. Fig. 6 shows the range of applicability of these white lubricants with a number of industrial component examples.

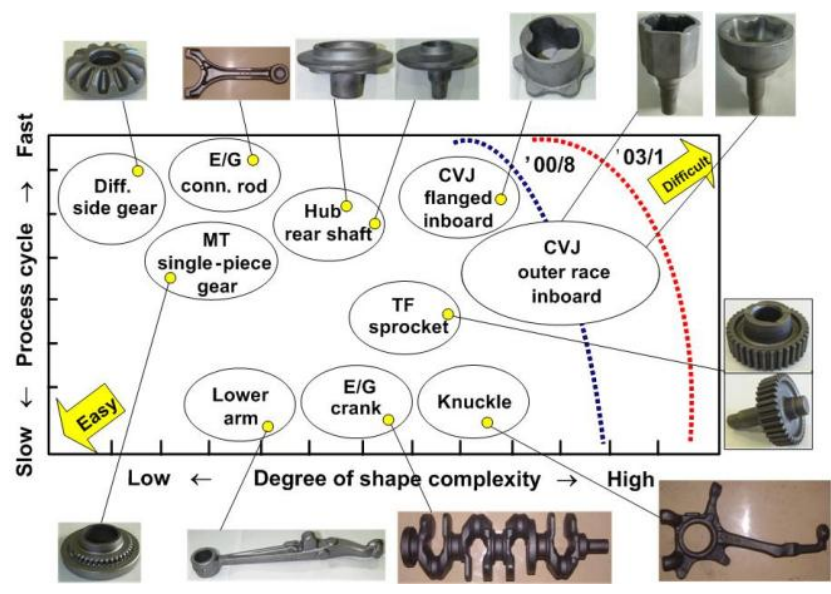

Fig. 6. Range of applicability of white lubricants [138].

Today Toyota has completely replaced black lubricants in warm and hot forging with white ones, which are claimed to have excellent oil separation properties and high recovery rate, reducing the amount of waste liquid per forging line to less than $10 \%$ of that of graphite based lubricants. They imply, however, drawbacks such as lower lubricity and more difficult die release. This eventually reduces die life if no special precautions are made such as considering the film thickness and spraying conditions to optimize die cooling. Studies of the influence on tool life of spray rate on the punch in warm forging of a CVJ (Constant Velocity Joint) show this to have large influence. High spray rate decreases the tool surface temperature and a white film of lubricant adheres to the punch nose, Fig. 7. At too low of a spray rate the film thickness becomes too thin and deteriorates into a blackish film on the tool due to excessive temperature, beyond $350^{\circ} \mathrm{C}$. Too high of a spray rate also leads to decreasing film thickness; an optimum appears with a tool temperature of $300^{\circ} \mathrm{C}$, which also gives optimum punch life, see Fig. 8 .

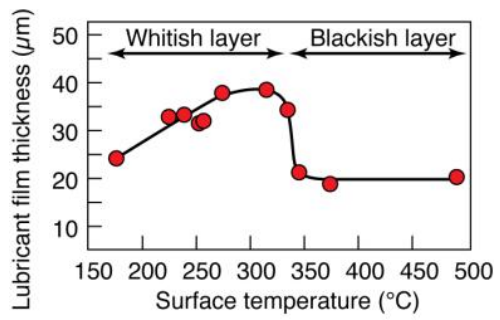

Fig. 7. Die temperature and thickness of dry lubricant film, [138].

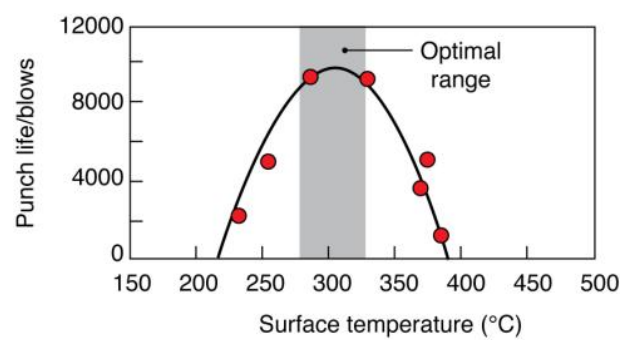

Fig. 8. Punch life as a function of tool temperature, [138].
Bariani et al. [21] have also studied cooling and lubrication efficiency in hot forging by combined experimental and numerical analysis determining optimum geometric configuration of spraying system and minimum quantity coolant.

\section{Rolling}

Cold as well as hot rolling is characterized by high volume production with corresponding large consumption of lubricant. Over the past two decades, advances in emulsion lubrication have allowed the proliferation of emulsions in metal forming operations, and especially metal rolling. An emulsion is a heterogeneous system, consisting of at least one immiscible liquid dispersed in another in the form of droplets whose diameters exceed $0.1 \mu \mathrm{m}$, [27]. A typical emulsion consists of roughly $95 \%$ water, with the remainder being oil, emulsifier and additives such as brighteners, biocides, detergents, etc. The application of emulsions has become prevalent not only because of the environmental and economic advantages; they also have performance advantages. Not surprisingly emulsions have better cooling efficiency than neat oils, as few fluids are better than water at conveying heat, but surprisingly an emulsion can lubricate almost as well as neat oil.

\subsection{Emulsion formulation}

Due to the difference in density of oil and water, buoyancy causes the phases to separate, i.e., emulsions are inherently unstable. To add stability, emulsions are aggressively agitated to achieve very small droplet sizes and tight distributions, or alternatively emulsifiers are added to the system. Emulsifiers are usually surfactants, although some formulations use macromolecules, fine particles and/or simple electrolytes as emulsifiers, [36].

An emulsion is formulated and provided by a lubricant supplier as a mixture of base oil, typically $80-95 \%$ by volume, emulsifier, and a recipe of additives including brighteners, antifoaming agents, biocides, lubricity additives, etc. Deionized water is added by the end user and the mixture is agitated to form the emulsion.

\subsection{Mechanisms of emulsion lubrication}

Overviews of studies and modelling of emulsion lubrication in metal forming are contained in $[135,180]$. Direct observations showed that some oil particles, especially the smaller ones, approaching the inlet zone were subsequently rejected, whereas the larger ones would be entrained [144,145,214]. Stay particles could only exist at one location in the inlet zone, and most particles moved around the contact zone as side flow. Volume flow calculations show that of the oil present in the emulsion, only $2-5 \%$ serves to lubricate the rolling operation, with the remainder serving no lubrication advantage. The implication is that the environmental and economic savings associated with emulsions could be compounded with better understanding of oil capture.

\subsection{Theoretical approaches}

A number of theoretical approaches have been forwarded to explain the behaviour of emulsions as lubricants. The main approaches are described in the following. 


\subsubsection{Plate-out}

Plate-out is the traditional approach explaining emulsion lubrication, [123,178,204]. It is schematically illustrated in Fig.9, after [181]. When an oil droplet is exposed to a metal, the anionic layer formed by the polar orientation of the emulsifier molecule induces droplets to absorb onto the surface. Once on the surface, the droplet spreads to the wetting angle, $\beta$, see Fig.9a. Thus, metallic surfaces exposed to emulsions can plate-out a layer of oil, with a resultant decrease in friction and increase in film thickness far greater than expected from the emulsion's bulk properties. Further, plated-out oil can cover the rolls or tooling, and is then available for subsequent operations. Only a small additional amount of oil is needed to plate-out in each revolution of the rolls to maintain this condition. The value of the plate-out theory is clear for low-speed conditions. Using a plate-out rationale, the ability of oil particles to wet a surface is important $[40,113,215]$, and it has been suggested that emulsions should be designed with controlled instability to guarantee full plate-out onto surfaces [126].

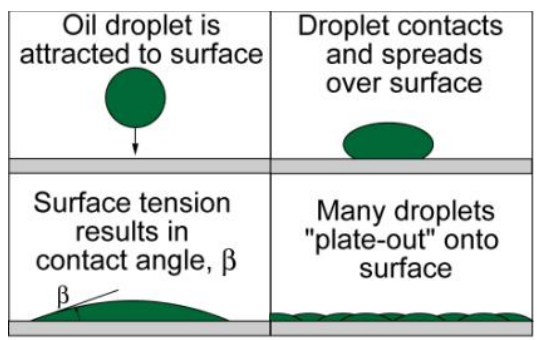

(a)

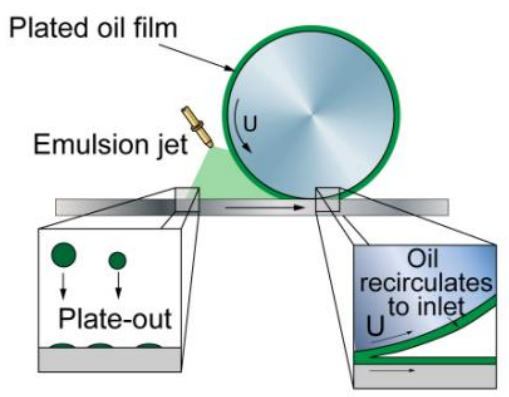

(b)

Fig.9. Illustration of the plate-out theory of emulsion lubrication, [181]. (a) Development of an oil plate; (b) mechanism of oil recirculation.

\subsubsection{Dynamic Concentration.}

The Dynamic Concentration Theory (DCT) is illustrated in Fig. 10. This theory was first proposed by Sakaguchi and Wilson [172] and later refined by Wilson et al. [210] and independently developed by Kimura and Okada [112,113]. Cassarini et al. [35] and Montmitonnet et al. [135] have developed additional aspects of emulsion behavior based on this approach, including emulsion supply issues. The model relies on the recognition that for real emulsion lubrication problems, the oil droplets are at least one order of magnitude larger than the ultimate film thickness. Experiments suggest a fluid film larger than that obtainable by water alone exist, thus it was suggested that oil droplets are preferentially entrained and flattened in the converging gap, squeezing out the water in the inlet zone, and concentrating dynamically while doing so.

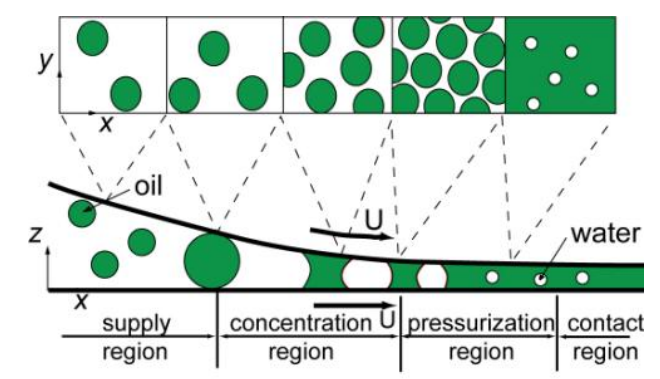

Fig. 10. The Dynamic Concentration Theory. Illustration of the droplet entrainment, oil concentration and pressurization region, [180].

Fig. 11 shows the dimensionless film thickness $H=h_{o} h_{o w}$ as a function of the supply oil concentration $\varphi_{s}$ and the capture coefficient $C$ representing the likelihood of particles to be entrained and the amount of droplet flattening before they can be considered to be penetration droplets. Parameters included in the analysis are mean oil droplet size and the Wilson-Waliwit film thickness $h_{o w}$ for neat oil, [209]. Curve fits from the DCT applied to experiments are shown in Fig. 11.

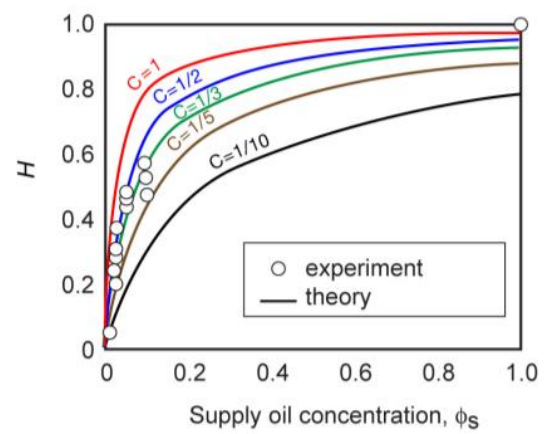

Fig. 11. Dimensionless film thickness in aluminium plate rolling with oil-inwater emulsion lubricants. Measured film thickness and curve fits from the Dynamic Concentration Theory for different capture coefficients, [179].

\subsection{Experimental testing of lubricants for rolling}

\subsubsection{Cold rolling}

Cold rolling lubricant evaluation is very demanding because of the stringent surface requirements on the rolled product. Most lubricants are evaluated to ensure lubricity. Also, bulk properties such as viscosity and pressure exponent of viscosity are designed through base oil blending to ensure that the desired film thickness is achieved, usually using the Wilson-Walowit equation [209] as a reference. This equation requires viscosity, which is readily measured in a number of widely available viscosimeters, and the high pressure viscosity, which is more difficult to obtain. Two methods used to obtain the pressure exponent of viscosity for use in a Barus law [22] are to a) use Azushima's [16] oil drop test or direct film thickness measurement using fluorescence in a metal rolling mill or b) obtain this information from elastohydrodynamic lubrication (EHL) rigs. Superior EHL rigs have been developed in the past decade or so by the Spikes and his group [34] and marketed by Plint, although a number of other designs are also available [198]. These rigs also allow measurement of tractions in metal rolling, allowing evaluation of lubricity [54], and direct observation of lubrication mechanics. For example, direct observation of emulsion oil droplets using a high speed camera combined with optical microscopy was done by Yang et al. [214]. 
The main drawbacks of EHL experiments are the absence of new surface generation and associated thermal effects. For this reason, laboratory scale rolling mills are needed for proper evaluation of lubricants $[10,17,46]$. Such mills typically have a two-high or four-high configuration. Aside from qualitative evaluation of anti-staining, antigalling and pickup prevention and the like, these instruments allow for evaluation of friction and lubricity $[11,19,207]$ or film thickness [16], allowing inference of high pressure lubricant properties.

Dubar et al. have developed an upsetting-rolling test for simulation of cold rolling to study the influence of roll parameters like reduction, speed and tool temperature on friction and lubricant film breakdown applying emulsions of mineral oil with additives of fatty acids, sulphur and phosphor compounds. They compared their results with experiments in an industrial Sendzimir rolling mill and concluded that the combination of simulative testing with numerical modelling provided a good method for optimisation of industrial rolling parameters, $[45,50,124]$.

\subsubsection{Hot rolling}

Azushima et al. have developed simulative lubrication test stands for cold as well as hot rolling, [10,17]. Both test stands include a main stand performing the rolling and a sub stand delivering back tension causing a larger peripheral speed of the main roll than of the work piece to ensure skidding (neutral plane moved to the exit). The main stand is provided with load cells and a torque transducer enabling determination of the average coefficient of friction $\mu$ during testing as: $\mu=M / P R$, where $M$ is the torque, $P$ is the load and $R$ is the roll radius. As regards hot rolling an infrared furnace heating a strip with length of $960 \mathrm{~mm}$ to a maximum temperature of $1100^{\circ} \mathrm{C}$ is located between the sub stand and the main stand. A comprehensive test program has been carried out studying the performance of a large number of lubricants based on five different base oils (see Table 4) with various additives: Colza oil (vegetable oil based on the seeds of Brassica campestris, Swedish turnips), mineral oils and synthetic ester oils with low as well as high viscosity. Additives investigated include oleic acid, fatty oil sulphide, graphite, $\mathrm{MoS}_{2}$ and Mica, [18]. The lubricants were tested in rolling $9 \mathrm{~mm}$ JIS SPHC (hot rolled, mild C-steel) at $800^{\circ} \mathrm{C}$ with a $0.3 \mathrm{~mm}$ thickness reduction. The peripheral speed of the main roll stand was $50 \mathrm{~m} / \mathrm{min}$ and the ratio between roll and strip velocity was 20 .

Fig. 12 shows the coefficient of friction as a function of the emulsion concentration for the three different base oils. The two lubricants with boundary lubrication effects give lower friction than the mineral oil, which does not have this effect. In all cases friction decreases with increasing emulsion concentration up to $1 \%$ after which it reaches a constant value. This is explained by the change in lubrication mechanisms when changing from low

Table 4

Base oils investigated in hot rolling test, [18].

\begin{tabular}{cc}
\hline Lubricant & $\begin{array}{c}\text { Type of base oil and kinematic viscosity at } \\
\mathbf{4 0} \mathbf{C}\end{array}$ \\
\hline A & Colza oil, $35 \mathrm{~mm}^{2} / \mathrm{s}$ \\
B & Mineral oil with low viscosity, $40 \mathrm{~mm}^{2} / \mathrm{s}$ \\
C & Synthetic ester oil with low viscosity, $50 \mathrm{~mm}^{2} / \mathrm{s}$ \\
D & Mineral oil with high viscosity, $170 \mathrm{~mm}^{2} / \mathrm{s}$ \\
E & Synthetic ester oil with high viscosity, $200 \mathrm{~mm}^{2} / \mathrm{s}$ \\
\hline
\end{tabular}

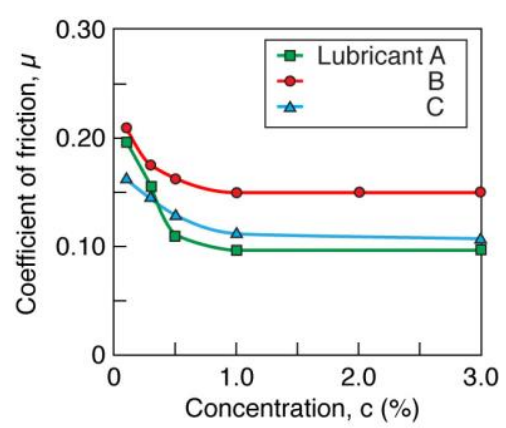

Fig. 12. Coefficient of friction versus emulsion concentration for: A. Colza oil, B. Mineral oil, low viscosity, C. Synthetic ester, low viscosity.

to high emulsion concentration. At higher emulsion concentration effective separation of the workpiece and tool surface is obtained, whereas contact between workpiece asperities and roll surface appears in case of low emulsion concentration. Tests of similar oils with low and high viscosity at $40^{\circ} \mathrm{C}$ show the higher viscosity to provide lower friction in the range where asperity contact occurs $(c<1 \%)$, whereas viscosity shows no influence on friction at higher concentration, where full separation appears [18].

The Finnish company Pinifer has developed a biodegradable hot rolling oil based on tall oil (from pine tree), [83]. They claim the benefits to be: decreasing rolling load and energy consumption, reduced wear and improved surface quality of the rolled sheet.

\subsection{Limits of lubrication of cold rolling}

The onset of pick-up and galling is assumed to be directly related to the interface temperature. Fukuyama et al. [57] report from cold rolling of low C-steel with a conventional roll that pick-up occurs when the temperature exceeds the lubricant film breakdown temperature. Using the simulative rolling test mentioned above combined with superimposed relative sliding, Jimbo et al. [97] have confirmed this, studying temperature rise and limit of lubrication in cold rolling of low C-steel lubricated with paraffin oil of kinematic viscosity of $80 \mathrm{~mm}^{2} / \mathrm{s}$ at $20^{\circ} \mathrm{C}$. Tests were carried out in the peripheral speed range of 24-143 $\mathrm{m} / \mathrm{min}$ with a roll diameter of $74 \mathrm{~mm}$ and the ratio between roll and strip velocity was 10 . The interfacial temperature was measured by establishing a thermoelectric circuit with the contact interface as the hot junction between the thermocouple wires. Fig. 13 shows the interfacial temperature in cold rolling at 143 $\mathrm{m} / \mathrm{min}$, where the critical temperature causing lubricant failure is approximately $130^{\circ} \mathrm{C}$.

Theoretical calculations of the interface temperature prove good agreement with the measurements, see Fig. 14, implying the

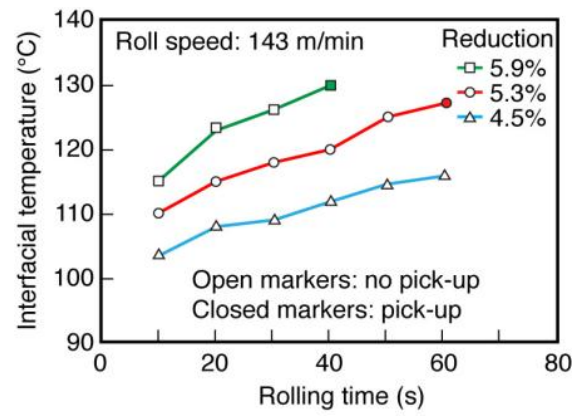

Fig. 13. Interfacial temperature and limit of lubrication in cold rolling of low C-steel lubricated with paraffin oil and a roll speed of $24 \mathrm{~m} / \mathrm{min}$ [97]. 


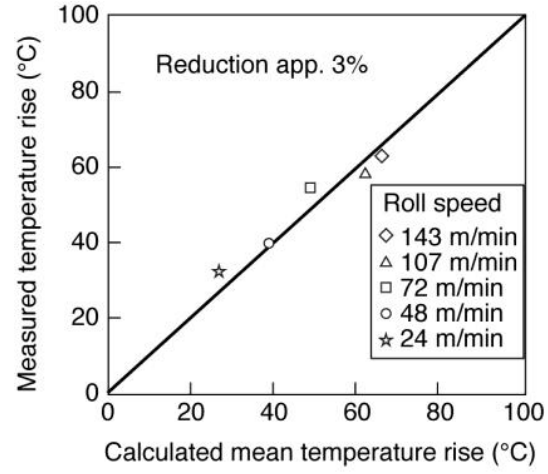

Fig. 14. Comparison between measured and calculated temperature rise in contact interface, [97].

possibility of predicting lubricant failure and galling in cold rolling, by combining simulative testing of limits of lubrication with calculations of interfacial temperature in practical roll production.

\section{Sheet forming}

Sheet stamping production in advanced high strength steels and stainless steels implies very severe tribological conditions. This is partly due to their high strength, implying large contact stresses and temperatures at the tool/workpiece interface, partly due to the microstructure of the sheet materials involving multiphase structures and large tendency to pick-up and galling when the lubricant fails. The problems have been solved by adopting chlorinated paraffin oils, which are highly reactive creating a boundary film by reacting with the workpiece material, often combined with CVD or PVD coated tools improving the galling resistivity.

The chlorinated paraffin oils contain short-chained C10-13 as well as medium-chained $\mathrm{C} 14-17$ chloroparaffins and they are suspected to have harmful effects on human health. The EU classification of short-chained chlorinated paraffins is carcinogenic in category 3 with risk phrase R40: "Limited evidence of a carcinogenic effect". Due to the chloroparaffins" persistent and bio-accumulating properties increasing concern towards the disposal problems further emphasizes the attempts to abandon the lubricants, and legislation has therefore been aimed at minimizing the use in EU as well as Japan for the last decade, $[4,5,90]$.

\subsection{Stamping with dry film lubrication}

Stamping lubricants can be divided into oil-based liquid lubricants and dry film or coil lubricants (DFL). The liquid lubricants may be mineral oils or emulsions. Dry film lubricants are divided into water-soluble dry film lubricants and water-free dry film lubricants (the so-called "hotmelts"). Water-soluble dry film lubricants are applied in amount of $0.5-1.5 \mathrm{~g} / \mathrm{m}^{2}$ at the rolling mill. They stick to the surface of the stamped sheet parts and offer sufficient corrosion protection but are not compatible with most adhesives used in automotive body construction [133]. The water-free dry film lubricants are also applied on the sheet material in small amounts at the rolling mill. Besides their superior drawing performance compared to oil-based lubricants, the most important advantage is their compatibility with almost all commonly used adhesives. In today's automotive stamping plants, DFL is increasingly popular, due to improved performance, cleanliness and reduced requirements for recycling and disposal [39,205]. In addition, DFL: a) provides uniform coating thickness on the sheet blanks, b) reduces the amount of lubricant (typically $0.5-1.5 \mathrm{~g} / \mathrm{m}^{2}$ vs. oil-based lubrication $1.5-3.0$ $\mathrm{g} / \mathrm{m}^{2}$ ), c) may eliminate washing of stampings which are necessary with wet lube, d) is compatible with assembly operations (welding, bonding, clinching and riveting), e) is more environmentally benign than the petroleum based wet lubes. On the other hand, DFL has no cooling effect and makes it difficult to remove deposits of metal debris left on the die surface.

Altan et al. have carried out several larger investigations on new lubricants for automotive sheet metal forming as substitutes to petroleum based oils $[39,108,110,111]$ based on a system of laboratory tests emulating the varied conditions in sheet metal forming. The tests include Twist Compression Test (TCT), Deep Drawing Test (DDT), Ironing Test (IRT) and Bending Under Tension test (BUT).

Testing was performed on mild steel AKDQ 1008, [39], HSLA steel, ASTM A1011, [39,108], Advanced High Strength Steel (AHSS), DP 500, DP 600, with and without zinc coating, $[110,111]$ with straight mineral oil, water based oil emulsions, dry films, chlorinated water emulsions and polymer films. Tool materials were uncoated AISI D2, Vancron 40 (a nitride alloyed PM HSS further described in section 8.1.2), Spheroidal graphite cast iron, as well as CVD and PVD coated tools. In deep drawing ranking of the lubricants was based on measurements of the maximum drawing force as well as the the size of the remaining flange. In ironing performed with reductions in the range 4-9\% ranking of the lubricants was done by measuring the load-stroke curves and the relative wall thinning. Both tests showed the two polymer coatings to perform best.

By considering heat transfer, a thermal-mechanical coupled simulation was conducted to predict the temperature increase and its distribution in the die and deformed sheet. BHF 30 ton and a friction coefficient $\mu=0.05$ were selected for the simulation conditions. Fig. 15 presents the temperature distribution in the fully deformed cup at $80 \mathrm{~mm}$ stroke as well as in the tool. Maximum temperature is found in the die radius region, where lubricant film breakdown also normally occurs if lubrication is insufficient.

Together with BMW, Merklein and Geiger et al. $[131,132,166]$ have worked on the replacement of mineral oil with dry film lubricants in aluminium sheet forming. The workpiece material was hot rolled AlMgMn alloys typically used with two different surface textures, MillFinish (MF) and Electro Discharge Textured (EDT), both with different roughness levels. The MF sheet is normally used for interior sheet and structure parts, whereas the EDT sheet is state-of-the-art for skin panels, [165]. Four different lubricants were tested in plane strip drawing test as well as in deep drawing. The lubricants are listed in Table 5. The results showed especially the water-free coil lubricant $\mathrm{C}$ and the mineral oil $\mathrm{A}$ to be quite independent on surface roughness and amount of lubricant within the range $0.9 \leq \mathrm{R}_{\mathrm{a}} \leq$ $1.6 \mu \mathrm{m}$ and $0.5-1.5 \mathrm{~g} / \mathrm{m}^{2}$, respectively, [132]. Based on the good resultsobtained with the water-free dry film this has been introduced in production of a number of aluminium parts at BMW, see Fig. 16.

On steel sheets the maximum limit for compatible amounts of mineral oil lubricant for later assembly is usually $3.0 \mathrm{~g} / \mathrm{m}^{2}$, while in special cases it goes down to $1.5 \mathrm{~g} / \mathrm{m}^{2}$. With higher amounts the components have to be washed after forming. Tolazzi, et al. [197] have investigated the possibility of applying dry film lubricant for sheet forming of steel as an alternative to 

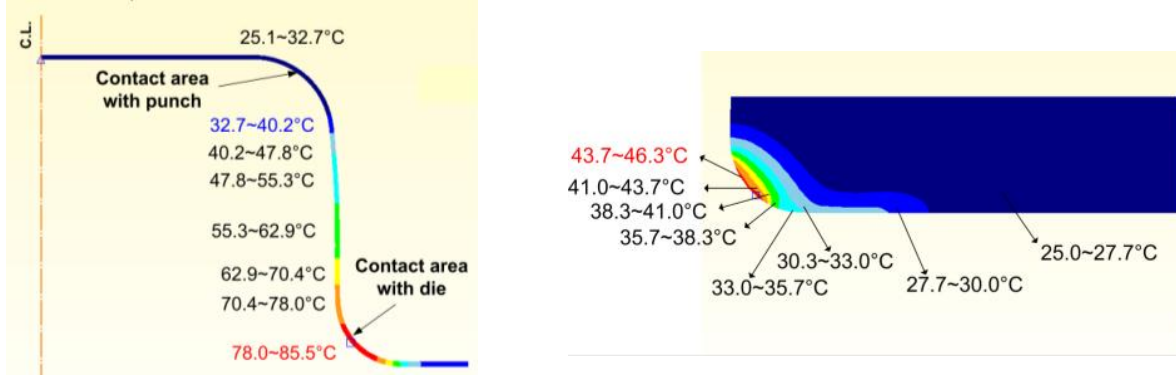

Fig. 15. Temperature distribution in final formed cup and drawing die, [111].

Table 5

Lubricants tested in $\mathrm{Al}$ sheet forming, [166].

\begin{tabular}{ccc}
\hline Lubricant & Type & Amount $\mathbf{g} / \mathbf{m}^{2}$ \\
\hline Lub A & Mineral oil KTL N 16 & $\geq 3.0$ \\
& Viscosity $160 \mathrm{~mm}^{2} / \mathrm{s}$ at $40^{\circ}$ & \\
Lub B & Water-soluble dry film & $0.5,1.01 .5,2.0$ \\
& Drylube C2 & \\
Lub C & Water-free dry film & \\
Lub D & Drylube E1 & 0.5 \\
\hline
\end{tabular}

Process with liquid, mineral oil based lubricants

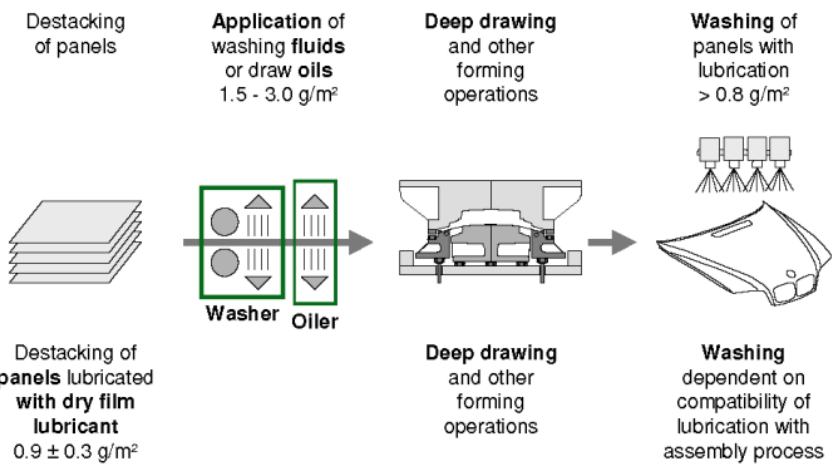

Process with dry film lubricants or hotmelts

Fig. 16. Comparison of a process chain with liquid or dry lubricant, [197].

lubrication with mineral oil. Fig. 16 shows the difference of the two processes. Applying a dry film lubricant in an amount of 1 $\mathrm{g} / \mathrm{m}^{2}$ is sufficient for most forming operations implying that washing in many cases can be avoided [166]. The drylube E1 investigated in [197] is a water-free lubricant applied at the rolling mill. This so-called "hotmelt" does not run off the panels" surface and offers good corrosion protection to all kinds of steel qualities. It furthermore has better performance in drawing operations and it complies with almost all commonly used adhesives. Four different steels were examined, two mild steels, galvanised and electro-galvanised and two high strength steels, $\mathrm{H} 400$ and $\mathrm{H} 300$, the latter with a ground surface. Testing in deep drawing showed it possible to reduce the amount of lubricant from $1.0 \mathrm{~g} / \mathrm{m} 2$ to $0.5 \mathrm{~g} / \mathrm{m} 2$ with only a slight reduction of the process window if suitable texturing of the sheets were present.

Groche et al. [64] report the influence of lubrication on galling of hot-dip galvanized mild steel in deep drawing. Galling is especially pronounced in connection with draw beads, and a simulative draw bead tester with multiple stroke capability is applied to simulate production conditions. The tested sheet was
EDT textured deep drawing steel, DX54Z, and the tool material was globular cast iron, GGG70L. Besides testing as-received sheet provided with $\sim 1 \mathrm{~g} / \mathrm{m}^{2}$ anti corrosion oil, tests were performed with additional lubrication with the same oil, deep drawing oil, sprayable drylube and roller-applied hot-melt drylube. Whereas friction was lowered by adding sprayable drylube, all the other lubricants resulted in increased friction. In all cases additional lubrication resulted in significant increase of galling. Microsections of drawn sheet showed the mechanism of re-adherence of abraded zinc onto the sheet surface, which was predominant in case of no additional lubrication. Additional lubrication separates the abraded particles form the sheet leaving the tools surface as adhering partner resulting in galling.

Like the automotive industry the can manufacturing industry is of enormous scale worldwide with approximately 400 billion cans produced of all types every year, and roughly one-half of these made for food and beverage products. Almost all food containers are made from steel-base stocks, while beverage containers are aluminum or steel, [74]. Current can making includes the sheet-metal forming operations of drawing, redrawing, and ironing, all of which require proper lubrication to ensure overall process efficiency. Residual liquid lubricant collects on the workpiece and must be removed, as it can be toxic and contributes adversely to product taste. This is done during a solvent wash cycle.

The interior can surface is not suitable for food contact after ironing, because the metal will adulterate food quickly, either from metal particulate contamination or chemical attack. This is prevented by isolating the can wall from the contents with either a thermoplastic or thermosetting resin which is safe for food contact. This is done by dissolving the polymer in a carrier fluid, usually methyl ethyl ketone or equivalent, and applying this solution to can interiors. After application of the resin/carrier fluid spray, an oven-curing operation allows the resin to bond to the interior surface, while the toxic carrier fluid boils off and is released as a volatile organic compound (VOC). In order to make this harmful by-product environmentally safe, an afterburner is used to reduce it to water vapour and carbon dioxide.

An alternative to the traditional process is to use a polymer laminated steel sheet stock. This polymer is a thermoplastic, similar to those applied to the traditional can via spray deposition, and it is naturally suitable as the food contact surface. However, to be successful, the polymer would need to fulfil the following requirements: a) Survive the manufacturing operations without rupture, b) Possess low friction properties to allow elimination of lubricants, and hence cleaning operations to remove lubricants from the cans before filling, c) If used on can exteriors, it needs to be semi-permeable or suitable for decoration and printing. 
Jaworski, et al. [95,96] demonstrated that laminated polymer-coated sheet steels can be used as ironing stocks. Experiments found that low die angles result in a successful ironing, while large die angles result in shaving of the polymer film off of the steel. The critical die angle at which ironing occurs was shown to be a function of the laminate strength, and was found to be $6^{\circ}-9^{\circ}$ for the investigated materials. Recently, SellesCanto et al. [185] extended the concept of ironing with a polymer coated steel to a three-layered polymer. Such a coating consists of a "tie" layer bonded to the steel sheet-metal, a "top" layer at the exterior and a "bulk" layer between these two polymers. This system is more flexible, and allows tailoring of the thicknesses and material properties for particular applications. For example, the top layer can be formulated for frictional purposes and with permeability to allow printing, the tie layer can be selected to maximize adhesion to the steel and the bulk layer can be selected to improve ironability.

In Japan replacement of petroleum based lubricants has been obtained by development of a combined drawing, stretchredrawing and ironing process of aluminium cans, using a polyester film as lubricant, [91-93], see Fig. 17. The redrawing with a die radius less than the sheet thickness and with high back tension caused by the bending and flange drawing-in reduces the required blank thickness and reduction in the subsequent ironing process. Due to the process development and use of solid polymer coating as only lubricant the load on environment is claimed to be significantly reduced regarding $\mathrm{CO}_{2}(67 \%)$, solid waste $(99.7 \%)$, electricity consumption (50\%), water consumption (95\%), fuel gas consumption (67\%), [92].

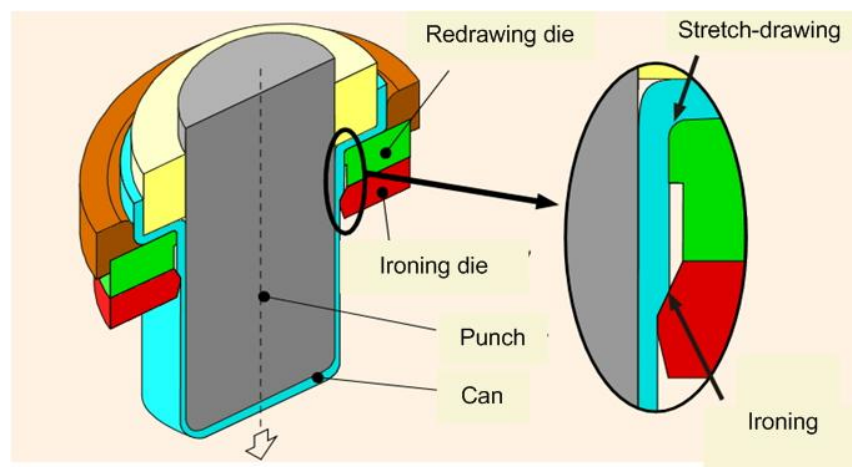

Fig. 17. Stretch-drawing and ironing of aluminium cans, [92].

\subsection{Alternatives to dry film lubrication}

In multistage deep drawing and ironing operations of materials prone to galling such as stainless steel and titanium, attempts to introduce polymer films have failed and several Danish and an EU research programme have focussed on developing alternative solutions $[25,82]$. In this connection a system of test methods representing the varied conditions in sheet metal forming have been developed including simulative tests: Bending-Under-Tension (BUT) [3], Draw-Bead-Test (DBT) [160], Strip-Reduction-Test (SRT) [1,2] as well as process tests: Deep-Drawing-Test (DDT) [2,161] and PUnching-Test (PUT), $[158,159]$. In order to emulate real production conditions, preheating of the tool temperature to typical production level is possible in all the simulative tests. Table 6 shows a small selection of the many lubricants tested.

As an example on BUT testing of AISI 304 with different lubricants Fig. 18 shows the results from five different lubricants
Table 6

Sheet forming lubricants tested

\begin{tabular}{|c|c|c|c|c|c|}
\hline No. & $\begin{array}{l}\text { Lubricant } \\
\text { manuf. }\end{array}$ & Code & Description & $\begin{array}{l}\text { Kin.viscos. } \\
40^{\circ} \mathrm{C} \mathrm{cSt}\end{array}$ & $\begin{array}{l}\text { Envirm. } \\
\text { hazard. }\end{array}$ \\
\hline L1 & Castrol & TDN81 & $\begin{array}{l}\text { Highly chlorinated } \\
\text { paraffin oil }\end{array}$ & 165 & Yes \\
\hline $\mathrm{L} 2$ & Castrol & PN226 & $\begin{array}{l}\text { Medium chlorinated } \\
\text { paraffin oil }\end{array}$ & 66 & Yes \\
\hline L3 & Pinifer & $\mathrm{P} 1$ & $\begin{array}{l}\text { Vegetable oil based on } \\
\text { fatty acid methylester }\end{array}$ & 205 & No \\
\hline L4 & Pinifer & P3 & $\begin{array}{l}\text { Vegetable oil based on } \\
\text { trimethylol propan } \\
\text { ester }\end{array}$ & 17 & No \\
\hline L5 & Chemetall & L6250 & $\begin{array}{l}\text { Water based } \\
\text { polymeric dispersion, } \\
\text { incl. water soluble } \\
\text { waxes, defoamer and } \\
\text { additives }\end{array}$ & - & No \\
\hline L6 & Houghton & CR5 & $\begin{array}{l}\text { Naphthenic mineral oil } \\
\text { without any EP } \\
\text { additives }\end{array}$ & 660 & No \\
\hline L7 & Rhenus & SF135 & $\begin{array}{l}\text { Mineral oil with } \mathrm{Ca}- \\
\mathrm{P} \text { - and S-additives }\end{array}$ & 135 & No \\
\hline L8 & Rhenus & CXF125 & $\begin{array}{l}\text { Mineral oil with Ca-, } \\
\mathrm{P} \text { - and S-additives }\end{array}$ & 125 & No \\
\hline L13 & Int. Comp. & IC345 & $\begin{array}{l}\text { Commercial drawing } \\
\text { grease }\end{array}$ & 5000 & No \\
\hline
\end{tabular}

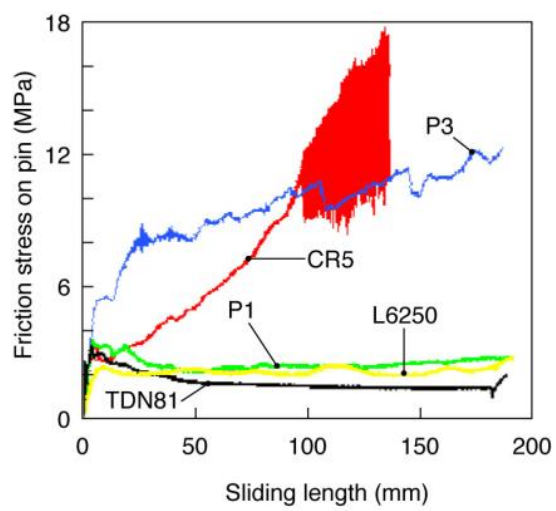

Fig. 18. Friction stress versus sliding length in BUT testing of AISI 304 strips against PM HSS with different lubricants. Tools preheated to $\mathrm{T}=70^{\circ} \mathrm{C}$ except for $\mathrm{CR} 5$, where $\mathrm{T}=60^{\circ} \mathrm{C},[25]$. Curve legends refer to lubricants listed in Table 6.

at a tool rest temperature of $70^{\circ} \mathrm{C}$. It is noticed that $\mathrm{P} 1$ and the polymer coating L6250 perform similarly to TDN81, whereas P3 and mineral oil CR5 show very poor performance with much higher friction that increases with the sliding length. As regards the mineral oil, which was tested at $60^{\circ} \mathrm{C}$, since it broke down immediately at $70^{\circ} \mathrm{C}$, the large oscillations at sliding lengths above $100 \mathrm{~mm}$ are due to stick-slip. Visual inspection of the strips and the tool surfaces showed severe galling when using P3 and CR5 corresponding to these measurements, whereas slight galling was observed with P1. No galling was observed with TDN81 and the decreasing friction with increasing sliding length observed for TDN81 may be attributed to chemical reaction with the tool surface forming a boundary film at elevated temperature. If testing were done at room temperature all lubricants performed 
well, implying that it is vital to test at temperatures normally seen in production.

In the strip reduction test galling is quantified by surface roughness measurements across the strip after testing, [1,2]. With increasing sliding length the tool becomes heated due to workpiece deformation and friction implying eventual breakdown of the lubricant film. From Fig. 19 it is noticed that the chlorinated paraffin oil and the polymer coating are sustaining the test even after $270 \mathrm{~mm}$ sliding length, whereas P1 and CR5 break down at $120 \mathrm{~mm}$ and $150 \mathrm{~mm}$, respectively. Preheating of the tool results in earlier breakdown.

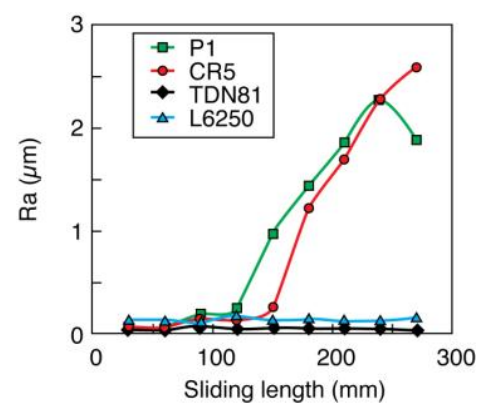

Fig. 19. $R_{a}$ as function of sliding length in strip reduction testing of stainless steel, AISI 316 against PM HSS with different lubricants, [25]. Curve legends refer to lubricants listed in Table 6.

In the EU project [82] a number of different environmentally benign oils were tested in production as alternatives to chlorinated paraffin oil. A progressive tool for production of a pump cover in stainless steel including deep drawing, collar drawing, ironing and punching operations were provided with transducers measuring process as well as backstroke forces and tool temperatures in the most critical collar drawing and ironing operation, see Fig. 20, Friis et al. [56].
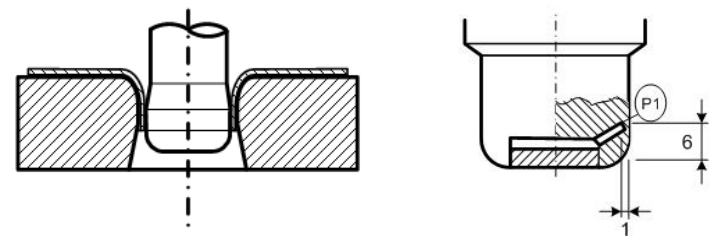

Fig. 20. a) Schematic outline of combined collar drawing and ironing operation, b) punch nose with insert and channel for mounting of thermocouple.

After screening tests of various lubricants and tool coatings the following lubricants were selected for the production test: the chlorinated paraffin oil PN226 and the environmentally benign oils Rhenus SF135 and Rhenus CFX125, see Table 6. Tool materials tested in the critical ironing operation were Vancron 40 and TiAlN coated PM HSS.The production tests using Vancron 40 tools showed that SF135 lubricant was practically useless and galling was initiated immediately from the start of the test regardless of the production speed. CXF125 performed significantly better, showing no galling at $50 \mathrm{spm}$ while after approximately 700 strokes at 100 spm galling appeared causing an increase in temperature as well as process and backstroke force. The chlorinated paraffin oil performed well even at 100 spm. Using the TiAlN coated tool and CXF125, no galling was observed at the maximum production speed of $100 \mathrm{spm}$. The same was the case for the chlorinated paraffin oil. Applying the poorer performing lubricant SF135 resulted in mild galling after 600 strokes at $100 \mathrm{spm}$. The performance of the individual tribosystems was consistent with the results from the laboratory testing using the strip reduction test.

The tool temperature development with stroke number was calculated in the combined collar drawing and ironing operation for the two different production speeds, 50 and $100 \mathrm{spm}$. Fig. 21 shows the results compared with the measured average values in each stroke. It is noticed that temperature increases rapidly, reaching a steady state within two minutes. The results suggest that the maximum thermal load may be lowered significantly by lowering production speed, leading to lower risk of galling. This correlates well with the production experience at Grundfos.

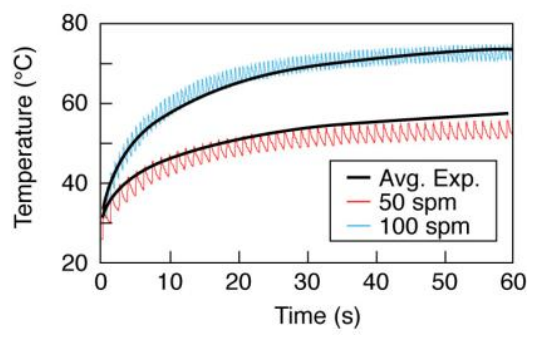

Fig. 21. Development of temperature in punch in combined collar drawing and ironing as a function of time and production speed.

Rao and Xie, [170], have tested boric acid, $\mathrm{H}_{3} \mathrm{BO}_{3}$, as a lubricant for sheet forming of aluminium with good results. The boric acid forms a strong, chemically bonded film on oxidized aluminium. Testing in deep drawing and stretch forming proved it to produce friction as low as teflon, and it has the benefits of being environmentally benign and easy to remove.

Mori et al. [136] have developed an electrochemical coating technique providing titanium sheet with an artificial layer of oxide for prevention of seizure in multistage deep drawing and ironing. Using aluminium bronze dies and commercially coloured sheets lubricated with calcium stearate powder it was possible in a 7 stage progressive tool to produce cups with a height/diameter ratio of 6 without intermediate annealing, avoiding the use of chlorinated paraffin oil.

\subsection{Manufacturers developing environmentally acceptable lubricants for sheet metal forming}

A few lubricant manufacturers have established a niche in developing new, environmentally acceptable lubricants for sheet metal forming. The Finnish company Pinifer has special expertise in manufacturing biodegradable oils derived from tall oil (pine tree). These fatty acid ester based oils have been successfully introduced in deep drawing production having good lubrication and anti wear properties, good corrosion resistance, good compatibility with paints, coating and seals, [83].

The German company Rhenus Lub has developed environmentally benign lubricants for cold metal forming as well as metal cutting based on refined mineral oils with special additives of natural fatty components, synthetic esters, sulphur additives and PEP additives, [33,85]. They have had particular success with these oils in fine blanking of C-steel as well as alloyed steel and stainless steel. As mentioned in Section 6.2 they have also shown very good performance in multistage deep drawing and ironing of stainless steel.

The American company IRMCO Fluids produce oil free, low viscosity metal forming lubricants, [77]. When deformation 
heat is applied, the high solid polymers (HSM) thicken and attach to the metal surface creating a friction reducing film barrier. Cleaning of the formed components may be done with water or a mild alkaline solution. The lubricants have been successfully implemented in stamping and punching of mild steel, advanced high strength steel, stainless steel, aluminium and titanium.

\subsection{Sheet forming - warm/hot}

The increasing application of warm and hot sheet stampings in Al- and Mg-alloys as well as advanced high strength steels in automotive production calls for appropriate tribo-systems for these new applications. Facilities for testing such tribo-systems have been developed by Geiger et al. [61,62], Yanagida et al. [213] and Borsetto et al. [31,32]. Whereas determination of the coefficient of friction is realized in the work of Geiger et al. using a combined experimental, analytical and numerical analysis of cup deep drawing tests, Yanagida et al. developed an advanced strip drawing test for direct friction measurements. Borsetto et al. have investigated tribological aspects within hot stamping using a pin on disc test, a hole expansion test and a strip drawing test. The investigations show the coefficient of friction to be nearly independent of the used tool material, but strongly dependent on the tool temperature. Applying a coating on the tool improves the forming behaviour. A standard coating material is $\mathrm{AlCrNi}$ which lowers adhesion effects and reduces friction [62,122]. Results of all the investigations show the coefficient of friction in hot stamping under dry friction conditions to reach high values, between 0.4 and 0.6 , and increasing temperatures to cause increased values of the coefficient of friction. [62,213]. In order to reduce friction sometimes solid lubricants, e.g. boron nitride, are used. Under such conditions the coefficient of friction is lower, values about 0.3 seem to be characteristic [213].

\section{Punching and blanking}

Punching and blanking including fine blanking represent some of the most severe tribological conditions in metal forming. Normal pressure as well as temperature at the tool/workpiece interface is high but the most severe conditions are due to the formation of virgin metal surface in contact with the punch stem. Due to these conditions it is very difficult to ensure access of lubricant into the interface. In order to prevent galling under these severe conditions, chlorinated paraffin oils are normally applied eventually in combination with ceramic tool coatings. The most common interpretation of the lubrication mechanism involved when applying chlorinated paraffins is the formation of hydrochloric acid under the influence of humidity from the ambient air reacting with the steel surface to form a boundary film of $\mathrm{FeCl}_{2}$. Friction tests carried out in a dry, inert atmosphere reveal the same effect, $[117,140]$.

Klocke et al. [117] emphasizes that very little has been done to develop new, non-chlorinated lubricants for fine blanking. They studied fine blanking of $16 \mathrm{MnCr} 5$ steel (AISI 5115) with punches coated with TiCN investigating different types of new lubricants, see Table 7. Lubricant $\mathrm{C}$ is developed as a lubricant with good chemical bonding properties containing high amounts of EP additives, whereas lubricant D with high amounts of polar substance has better physical bonding properties. The results show very good anti-galling performance of the latter, whereas lubricant $C$ resulted in severe galling. Based on these studies they propose the mechanism of lubrication in fine blanking to be physisorption of the lubricant instead of chemisorption, which is
Table 7

Tested oils, [117].

\begin{tabular}{cc}
\hline Lubricant & Description \\
\hline A & $\begin{array}{r}\text { Commercial fineblanking lubricant with chlorinated } \\
\text { parafins and S-additives }\end{array}$ \\
C & $\begin{array}{r}\text { Non-chlorinated paraffin oil with high content of } \\
\text { polysulphide and anti wear additives, low content of } \\
\text { native ester }\end{array}$ \\
D & $\begin{array}{c}\text { Non-chlorinated paraffin oil with high content of } \\
\text { native ester and emulsifier, low content of polysulphide }\end{array}$ \\
\hline
\end{tabular}

reasonable considering that the punch is coated with an inactive coating of TiCN.

Olsson et al. $[158,159]$ have developed a process test for evaluation of punching lubrication measuring the backstroke force, which is very sensitive to pick-up and galling. Fig. 22 shows the maximum, nominal friction stress on the punch stem during backstroke versus the number of strokes for four different lubricants in punching $\varnothing 2.0 \mathrm{~mm}$ holes in $1.0 \mathrm{~mm}$ stainless steel sheet AISI 316. Punching with chlorinated paraffin oil PN 226 and with P1 shows insignificant pick-up and accordingly small and almost constant backstroke friction, whereas much larger backstroke friction increasing with the number of strokes is noticed with the pure mineral oil CR5 and the polymer coating, which both showed heavy pick-up on the punch stem. The poor performance of the mineral oil compared to the two other oils may be attributed to the fact that the latter two have chemically active additives reacting with the punch stem to form a boundary layer, while the mineral oil does not [159].

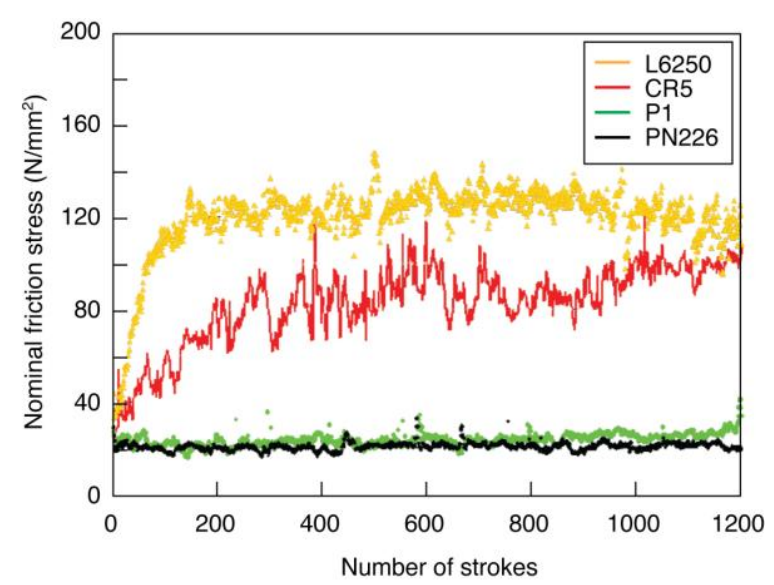

Fig. 22. Maximum punch stem friction stress during backstroke as a function of stroke number. Curve legends refer to lubricants listed in Table 6 .

Differential Thermal Analysis (DTA) proves that the chlorinated paraffin oil as well as P1 reacts chemically with the punch material, PM HSS, at elevated temperature implying that it is likely that a thin boundary film is established on the punch. The poor performance of the polymer coating is to be expected due to the small punch clearance $(10-15 \mu \mathrm{m})$ and the fact that this semi-solid film lubricant has difficult access to the clearance area between punch and die.

\section{Generic measures towards new tribo-systems}

Besides the development and introduction of new types of lubricants the environmental issues may be solved by generic measures such as development of: 1) Anti-seizure tool materials, 
2) Anti-seizure tool surface treatments, 3) Structured workpiece surfaces, and 4) Structured tool surfaces. In the following development of these generic measures is described.

\subsection{Anti-seizure tool materials}

\subsubsection{Carbide controlled tool steels}

Azushima et al. have studied the influence of tool materials on seizure and galling in cold rolling of low C-steel, [14,98]. They tested seven variants of high-chromium steel DS-A to DSG containing $\mathrm{M}_{7} \mathrm{C}_{3}$ carbides and four variants of high speed steel, HS-A to HS-D containing $\mathrm{MC}+\mathrm{M}_{6} \mathrm{C}$ carbides in their simulative cold rolling test, described in Section 5.4.2. The different tool materials were chosen to present a wide spectrum of carbide content and the area and mean spacing of carbides in the roll surface was measured and related to the onset of seizure and galling. The lubricant was a 5\% emulsion of tallow supplied by spraying at the entrance of the roll bite. Reduction was varied from $5-17 \%$ to determine the limit reduction before onset of seizure and galling.

Observations in [127] indicate that the $\mathrm{M}_{7} \mathrm{C}_{3}$ carbides tend to become progressively coarser during solidification, when the amount of carbides exceeds approximately $10 \%$. Based on this, Azushima et al. [14] suggest that the carbide morphology on the roll surface influence the anti-seizure properties of the tool surface significantly and moreover, that the mean carbide spacing seems to be a more relevant control parameter than the relative area of carbides. Fig. 23 confirms this hypothesis showing a linear decrease in limit reduction before seizure versus the mean carbide spacing. It is furthermore seen that the HSS rolls HS-A to HS-D follow the same trend.

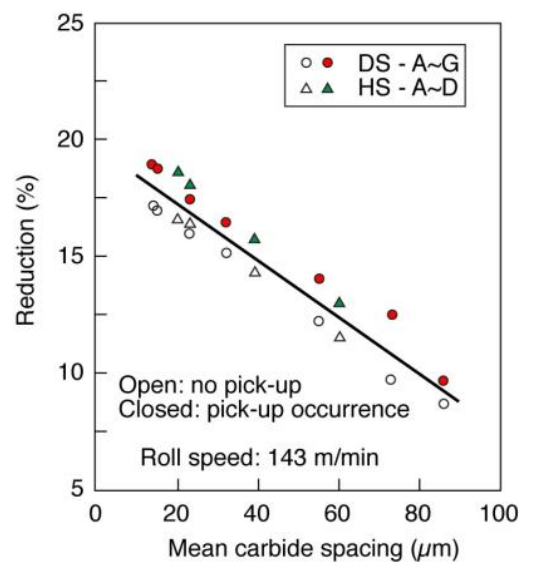

Fig. 23. Limit reduction to seizure versus mean carbide spacing, [98].

Based on these results, a tailored roll material in highchromium steel with controlled carbide morphology was manufactured by ingot casting resulting in a $6 \%$ carbide area [98]. The carbides were finely distributed by electro-slag remelting (ESR), forging and heat treatment. Roll dimensions were $\varnothing 440 \times 3316 \mathrm{~mm}$. The mean carbide spacing achieved in the carbide controlled roll was $55 \mu \mathrm{m}$ compared to more than 200 $\mu \mathrm{m}$ in a conventional 5\% chromium steel roll. The carbide controlled roll was compared to the conventional 5\% chromium steel roll with respect to the limit reduction before seizure inserting the two types of rolls in the final stand of a cold tandem mill for rolling 0.15-0.20 mm strip of low C-steel. Rolling speed was increased gradually under fixed reduction. Testing showed the limit speed for the conventional roll before pick-up occurred to be approximately $2000 \mathrm{~m} / \mathrm{min}$, whereas the carbide controlled roll caused no pick-up at a roll speed of $2300 \mathrm{~m} / \mathrm{min}$.

\subsubsection{Powder metallurgical nitrogen alloyed tool steel}

Uddeholm Tooling has developed a new, cold work tool steel Vancron 40, a powder metallurgical, nitrogen alloyed, high speed steel with excellent anti-galling properties [174,175]. Nitrogen increases the stability of vanadium nitride and the size of the hard phases become very small in the final tool material. Fig. 24 shows a comparison of the microstructure of Vancron 40 with conventional cold work tool steels and a PM HSS. Sverker 21 (AISI D2) and Sleipner (a refined version of AISI A2 and D2) have large carbides, up to $100 \mu \mathrm{m}$ in length and uneven distribution. The PM tool steel Vanadis 4 has small rounded off carbides, $<2 \mu \mathrm{m}$, which are evenly distributed. The nitrogen alloyed steel has a high fraction of more densely distributed $\mathrm{MN}$ phase consisting mainly of $\mathrm{V}(\mathrm{N}, \mathrm{C})$ (black phase in Fig. 24) and furthermore a small fraction of molybdenum rich carbides.
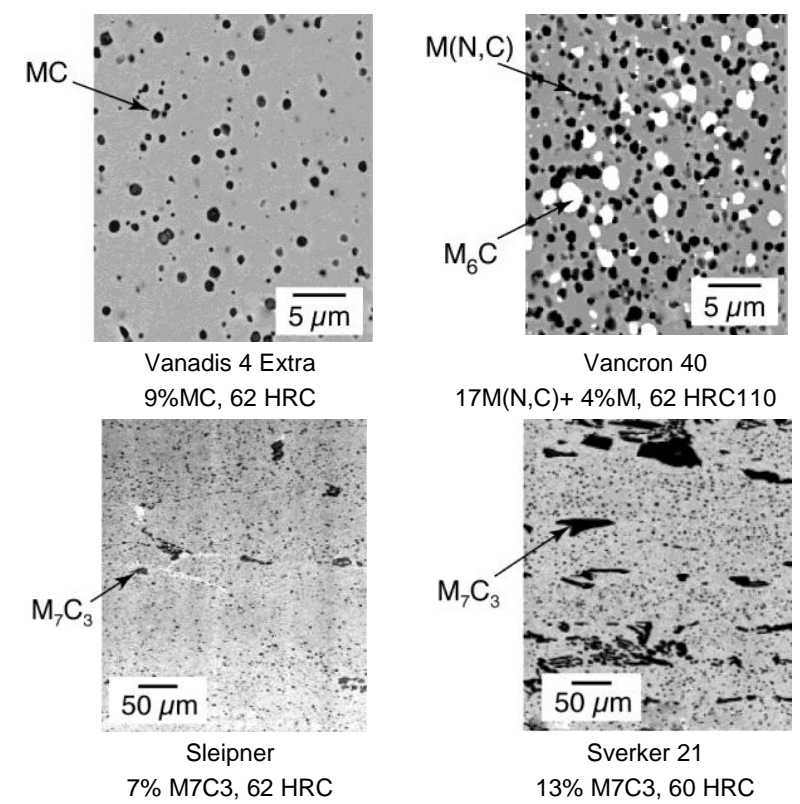

Fig. 24. Microstructure, hardness and amount of hard phase in four different heat treated cold work tool steels. Note the scaling is $5 \mu \mathrm{m}$ and $50 \mu \mathrm{m}$ for the PM steels and the conventional steels respectively, [175].

Table 8 shows mechanical properties of Vancron 40 compared to AISI D2 and Vanadis 6 (PM 3:2). Properties such as hardness, compressive strength, ductility and fatigue resistance of Vancron 40 are similar to those of Vanadis 6 and significantly better than those of AISI D2. Vancron 40 has excellent antigalling properties, much better than the other two steel grades as judged by a number of laboratory tests, $[69,173]$. Examples on industrial tests in cold forging of $\mathrm{Al} 6082$ steering parts with Vancron tool steel compared to conventional tool steels show improvements of tool life with a factor 10 or more. In deep drawing of stainless steel, AISI 304, a tool life of $>14.000 .000$ strokes has been obtained compared to 83.000 with PM Vanadis 23, 62HRC uncoated, 800.000 with PM Vanadis 6, 62HRC uncoated, 1.900.000 with PM Vanadis 10, 62HRC uncoated, and 6-8.000.000 with PM Vanadis 23, 62 HRC CVD coated. In these cases, characterised by cold forming of tribologically difficult materials (Al 6082 and stainless steel AISI 304) the good performance of Vancron 40 is especially due to the improved galling resistance. 
Table 8

Comparison of mechanical properties of different cold work tool steels, [174]. Relative scale: $1-10 ; 10$ best.

\begin{tabular}{|c|c|c|c|}
\hline \multirow{2}{*}{ Property } & \multicolumn{3}{|c|}{ Steel grade } \\
\hline & Sverker 21 & Vanadis 6 & Vancron 40 \\
\hline Hardness & $\leq 61 \mathrm{HRC}$ & $\leq 66 \mathrm{HRC}$ & $\leq 66 \mathrm{HRC}$ \\
\hline Compr. yield strength & $\leq 2500 \mathrm{MPa}$ & $\leq 3000 \mathrm{MPa}$ & $\leq 3000 \mathrm{MPa}$ \\
\hline Ductility & 2 & 10 & 10 \\
\hline Fatigue resistance & 4 & 10 & 10 \\
\hline Abrasive wear esistance & 7 & 10 & 8 \\
\hline Galling resistance & 1 & 3 & 10 \\
\hline
\end{tabular}

Observations of Vancron in SEM, Fig. 25 show the finely distributed hard phase to protrude slightly form the matrix surface. Combined with roughness mapping and LOM it becomes clear that the hard particles have a high height-to-width ratio and only a minor part of each particle is raised from the surface. It is the first author's opinion that this specially structured surface is essential for good anti-galling properties. The hard phase has no affinity to the workpiece material thus preventing adhesion and the intermediate matrix material is slightly lowered from the hard phase asperities enabling pockets of lubricants to be trapped in the surface. The good anti-galling properties of carbide controlled material for rolls discussed in Section 8.1.1 is possibly due to the same lubrication mechanisms. If tailored lubricants with ability to react with the tool steel matrix material are employed a boundary film may be established, which would further prevent galling.

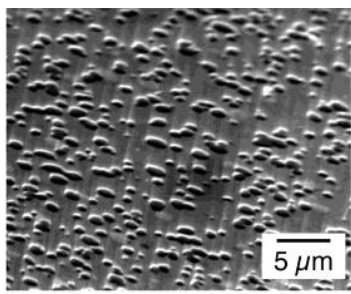

(a)

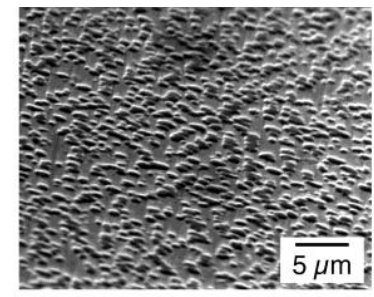

(b)
Fig. 25. SEM picture of polished a) Vancron 40, b) Vancron 50.

\subsubsection{Ceramic tools}

Ceramic materials are well-known to possess high wear resistance and anti-galling properties. Kataoka et al. [102] have carried out a comprehensive experimental investigation of dry deep drawing $\mathrm{Ti}, \mathrm{Al}$, mild steel, $\mathrm{Cu}$, stainless steel and zinccoated steel. Investigated ceramics were alumina, $\mathrm{Al}_{2} \mathrm{O}_{3}$, zirconia, $\mathrm{ZrO}_{2}$, silicon nitride, $\mathrm{Si}_{3} \mathrm{~N}_{4}$ and silicon carbide, $\mathrm{SiC}$, which were compared to conventional cold work steel AISI D2. Evaluation was based on determining the maximum drawing ratio, measurement of deep drawing force and SEM analysis of the drawn cup surfaces. As an example, Fig. 26 shows the limit drawing ratio, $\mathrm{LDR}$, determined for dry deep drawing of $\mathrm{Ti}, \mathrm{Al}$, mild steel and $\mathrm{Cu}$. It was concluded that no improvements were obtained in deep drawing of $\mathrm{Ti}$ sheet with ceramic tools. As regards $\mathrm{Al}$ sheet, $\mathrm{SiC}$ and $\mathrm{Si}_{3} \mathrm{~N}_{4}$ showed some improvements in the LDR but mild galling did appear. Regarding mild steel and $\mathrm{Cu}$ sheet the ceramic dies worked well, especially $\mathrm{SiC}$ and $\mathrm{Si}_{3} \mathrm{~N}_{4}$ and LDR's close to those obtained with lubrication were seen.

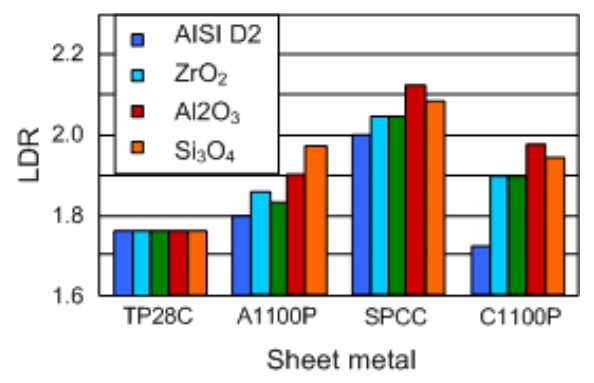

Fig. 26. Limit drawing ratio in dry deep drawing $\mathrm{Ti}, \mathrm{Al}$, mild steel and $\mathrm{Cu}$ with different ceramic tool materials [102].

Concerning dry deep drawing of stainless steel, the $\mathrm{Al}_{2} \mathrm{O}_{3}$ die gave very good results, again close to that with lubricated deep drawing. The punch load decreased with the number of drawn cups, which was explained by formation of an in-situ formed tribo-film of chromium and/or iron oxides working as a solid lubricant. As regards the zinc-coated steel, the $\mathrm{SiC}$ die had very good performance similar to that of lubricated deep drawing in uncoated die. In a later work Tamaoki et al., [194], points out the difficulties of machining ceramic dies of the mentioned type and propose as an alternative to apply an electro conductive die material, NPZ-28. With a die of this ceramic, dry deep drawing of mild steel sheet gave the same LDR as lubricated deep drawing with a conventional tool steel die and low tendency to galling.

Klocke and Kuwer [116] have evaluated three different silicon nitride ceramics with pin-on-disk tests as compared to hard tool coatings TiCN, WC/C and TiAlN with the purpose of finding the most suitable for lubricated deep drawing of stainless steel, AISI 304. They found $\mathrm{Si}_{3} \mathrm{~N}_{4}$ to perform well.

\subsection{Anti-seizure tool surface treatments}

The description below is a summary of the comprehensive description of different surface treatments of metal forming tools given in [6]. Surface treatments for tooling can be divided into coatings and thermochemical diffusion. Coating processes deposit an overlayer on the surface, while surface modifications alter the properties of the near-surface region without a new layer being added. Most thin-film coatings will not stand up to cold forging pressures when used alone. Such coatings are generally thinner than the case depth of a surface modification process. Under cold forging conditions, thin-film coatings deposited by physical vapour deposition (PVD) or chemical vapor deposition (CVD) are likely to crack or even delaminate. This immediately excludes the vast majority of commercially available PVD or CVD coatings as a treatment for forging tools. However, a PVD or CVD coating can be used for cold forging tools when deposited over another coating, or on top of a surface modified underlayer. In this instance, the underlying coating or surface modification process provides support for the overlay coating, [6].

\subsubsection{PVD and CVD coatings}

Many PVD and CVD coatings are single-layers. However, multi-layer coatings that combine the properties of the component layers, are becoming increasingly popular. Multilayer CVD coatings have been used for some time on cutting tool inserts, and several multi-layer PVD coatings have recently emerged too. An interlaye $r$ is sometimes deposited between a 
PVD coating and the substrate, to enhance adhesion. Some common PVD and CVD coatings are listed in Table 9. The most important requirements of a tool coating are high hardness and a low coefficient of friction. Tool wear decreases with increasing hardness. For long tool life, the surface hardness should be 1000 HV or higher, a condition satisfied by essentially all PVD and CVD coatings.

Table 9

PVD and CVD coatings, [6]. ${ }^{1} \mathrm{MoST}^{\circledR}$ is a $\mathrm{MoS}_{2} / \mathrm{Ti}$ composite coating

\begin{tabular}{cccc}
\hline Coating & $\begin{array}{c}\text { PVD or } \\
\text { CVD }\end{array}$ & $\begin{array}{c}\text { Typical coating } \\
\text { thickness, } \mu \mathrm{m}\end{array}$ & Hardness, HV \\
\hline TiN & PVD & $1-5$ & $2.300-2.900$ \\
TiCN & PVD & $1-5$ & $3.000-3.500$ \\
DLC & PVD & $1-10$ & $1.000-5.000$ \\
MoST $^{\circledR, 1}$ & PVD & $2-5$ & $1.500-2.100$ \\
TiC & CVD & $7-10$ & $3.000-3.200$ \\
TiC/TiN & CVD & $7-10$ & $2.600-2.800$ \\
\hline
\end{tabular}

\subsubsection{Thermochemical diffusion}

The main thermochemical diffusion processes for forming tools are summarized in Table 10. Thermochemical diffusion involves adsorption of an element such as carbon, nitride or boron on a heated metal substrate. This is followed by a chemical reaction between the element and substrate, and diffusion of the element into the metal. Several methods of diffusion can be used.

Table 10

Thermochemical diffusion processes, [6].

\begin{tabular}{lccc}
\hline Process & $\begin{array}{c}\text { Typical case } \\
\text { depth, } \mu \mathrm{m}\end{array}$ & $\begin{array}{c}\text { Surface } \\
\text { hardness, HV }\end{array}$ & $\begin{array}{c}\text { Typical process } \\
\text { temperature, }{ }^{\circ} \mathrm{C}\end{array}$ \\
\hline Carburizing & $75-1500$ & $700-900$ & $850-950$ \\
Nitriding & $75-750$ & $300-1.050$ & $500-570$ \\
Carbonitriding & $50-750$ & $600-850$ & $750-900$ \\
Nitrocarburizing & $25-750$ & $500-650$ & $560-670$ \\
Boriding & $25-125$ & $1.600-2.000$ & $820-980$ \\
TD process & $2.5-20$ & $3.200-3.800$ & $850-1050$ \\
\hline
\end{tabular}

The methods are: salt bath, gas, vacuum, ion (plasma), fluidized bed and pack cementation (solid). Process temperatures for diffusion can be as high as $1050^{\circ} \mathrm{C}$, which may result in distortion of a tool and loss of core hardness. Of the various diffusion treatments, carburizing results in the deepest case layers, but is restricted to C-steels and alloy steels. As with thinfilm coatings, the surface hardness for long tool life should be $1000 \mathrm{HV}$ or higher. This requirement restricts the choice of possible diffusion treatments to nitriding, boriding and the TD process, [6].

\subsubsection{Coated tools for cold forging}

The report [6] presents a larger investigation of attempts to replace phosphate coating and soap lubrication in cold forging of steel by applying anti-seizure tool coatings and new lubricants. The investigation concludes that three of the investigated tool treatments have potential to replace or at least reduce the use of phoscoating in cold forging. These are the MoST ${ }^{\circledR}$ PVD over TiC CVD coating, ion nitriding and the TD process.

One of the problems in applying PVD coatings for cold forging tools is the high hardness and Young's modulus compared to the base tool material leading to risk of coating fracture. Klocke et al. [114] report the development of a nanostructured multilayer coating (up to 40 layers) with intermediate bilayers of less than $20 \mathrm{~nm}$ with TiAlN layers closest to the substrate and on top of these a- $\mathrm{Al}_{2} \mathrm{O}_{3}$ layers. This coating was tested and proved to reduce Young's modulus and at the same time increase hardness, [125].

Dubar et al. [49] have performed a wear analysis of a cold forging tool for heading of a bolt in $34 \mathrm{Cr} 4$ steel comparing PVD with CVD coating with TiN of AISI M2 tool steel. A clear difference was notice showing the PVD coating to be chipped off at rather low number of operations leading to excessive friction. The better adherence of the CVD coating improved performance significantly. Osakada and Matsumoto [162] have studied dry metal forming of $\mathrm{Al}, \mathrm{Cu}$ and low $\mathrm{C}$-steel by ring test upsetting with cemented carbide tools CVD coated with TiC, TiC+TiCN+TiN, and PVD coated with TiN, TiAlN and DLC. They found that DLC coating resulted in low friction in dry forming of aluminium and that the oxide layer on steel resulted in very high friction in cold forging. Friction was very sensitive to surface roughness of the tool when forming dry.

With the objective of eliminating the use of phosphate coatings in cold forging, Groche et al. [63] tested a number of tool coatings in a cold extrusion test of steel wire. They found better wear resistance of CVD coated TiC+TiN than PVD coated $\mathrm{CrN}$ and TiN. Lubricants extended from ordinary extrusion oil to pigmented oil and an emulsion. CVD coatings with TiC+TiN and Me-C:H (DLC) show low friction and attempts to test in industrial production proved promising as regards substituting zinc phosphate layers by applying tool coatings.

\subsubsection{Coated tools for hot forming}

Matsumoto et al. [128,129] have tested TiAlN and DLC coatings on cemented tungsten carbide tools for hot forging of Mg-alloy without lubrication. They found the DLC coating to efficiently prevent seizure. Cesur et al. [37,38] have applied radio frequency magnetic sputtering technique to obtain good adhesion of cubic boron nitride, $\mathrm{CBN}$, to cutting tools in high speed steel obtaining favourable effects on cutting forces and tool wear. The coating is presently under trial in aluminium hot extrusion dies, [100].

\subsubsection{Coated tools for cold rolling}

Jimbo and Azushima, [99], have pointed out the problems of pick-up in ultrahigh-speed cold rolling of ultrathin gauge strip of low C-steel. In their earlier mentioned simulative roll tribo-test they showed significant improvement as regards galling resistivity, when using a roll with PVD coated TiN compared to a $5 \mathrm{Cr}$ roll.

\subsubsection{Coated tools for sheet metal forming}

Kim et al. [109] have tested PVD coatings with CrN, XNP and $\mathrm{TiCN}$ in a combined strip drawing and ironing test of uncoated as well as galvanized AHSS and found that TiCN showed the best efficiency to prevent galling. Klocke et al. [115] report the development and application of a new $\mathrm{ZrC}_{\mathrm{g}}$ tool coating which allows chlorinated paraffin oil to be replaced by a new environmentally benign, biodegradable, rape oil based lubricant. Successful testing has been performed in deep drawing of stainless steel AISI 304. Nakamura et al. [150] have tested DLC coating on high speed tool steel AISI M2 in lubricated forming of titanium sheet using a simulative sheet tribo test. They found high friction and severe galling with a non-coated 
tool, but significantly lower friction and no galling when using the DLC coated tool. Laboratory as well as field tests indicate that DLC and WC/C are promising die coating materials for forming of zinc-coated AHSS sheets, stainless steels and aluminium alloys that are prone to galling, [142,176,177]. Podgornik et al. have found amorphous hard carbon coatings to perform better than the commonly used PVD and CVD coatings, $[164,167,168]$.

Deep drawing without lubrication of sheet metals prone to galling such as aluminium, titanium and stainless steel can only be done using tool coatings or ceramic tool materials. Murakawa et al. [141,143] have succeeded in dry deep drawing of aluminium applying DLC coated tools. Application of DLC, however, has shown problems regarding peeling off due to insufficient adhesion to the substrate tool material at high loads. Solutions to this problem are increased substrate surface roughness and introduction of interface layers, [103]. Another problem regarding DLC is its low heat resistance implying that it is not feasible for forming at elevated temperature. Tamaoki et al. [195], have tested dry deep drawing of Al, mild steel and stainless steel with dies coated with diamond. They obtained almost the same LDR as in lubricated deep drawing in conventional die steel, Fig. 27, and no sign of galling in deep drawing mild steel and stainless steel, when polishing the coating down to $R_{z}=0.5 \mu \mathrm{m}$ quality, Fig. 28. A special ultrasonic technique was developed for polishing, [104]. The surface roughness of the drawn cup remained constant even after drawing 10.000 cups. As opposed to DLC, the CVD diamond coating has high heat resistance and Tsuda et al. [199] have applied it for dry deep drawing and ironing of $\mathrm{Mg}$ alloy at $200^{\circ} \mathrm{C}$ obtaining substantially lower friction and higher drawing ratio as well as smooth workpiece surfaces compared to lubrication with $\mathrm{MoS}_{2}$.

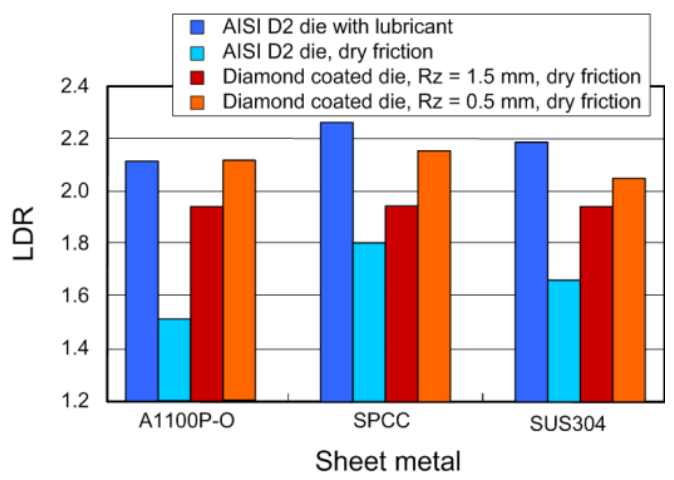

Fig. 27. Limit drawing ratio in dry deep drawing in diamond coated die compared to deep drawing in non-coated die, lubricated as well as dry, [195].

\subsubsection{Coated tools for punching and blanking}

Takaishi et al. [192] have investigated various punch materials and coatings for dry blanking of layered electrical steel sheet, where the intermediate, insulating glass coating causes excessive wear. Testing of punches in AISI D2 and PM HSS with PVD coatings of DLC, Me-DLC and EDC (Electro Discharge Coating) with $\mathrm{TiC}$ were carried out. All the coatings extended punch life by about a factor of three. Combining the EDC with cryogenic process treatment of AISI D2 resulted in an extension of tool life

by a factor of nine. Zajec et al. [219] report a similar investigation on blanking of layered electrical steel sheet, testing punch materials of PM HSS and cemented carbide with coatings of $\mathrm{AlCrN}, \mathrm{TiCN}$ and $\mathrm{TiAlN}+\mathrm{WC} / \mathrm{C}$. The best results were

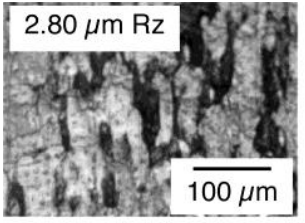

a) AISI D2 die, lubricated

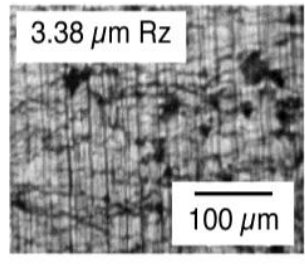

c) Diamond coated die

$\mathrm{Rz}=1.5 \mu \mathrm{m}$, dry friction

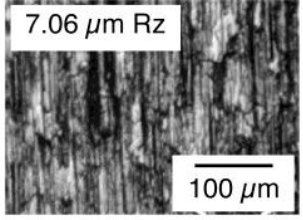

b) AISI D2 die, dry friction

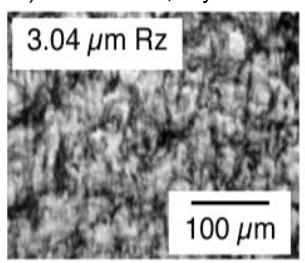

d) Diamond coated die $\mathrm{Rz}=0.5 \mu \mathrm{m}$, dry friction
Fig. 28. SEM micrographs of the surface of deep drawn cups in stainless steel, AISI 304, [195].

obtained by combining PM HSS with AlCrN.The Trumpff Group, [87] reports that the tool life for HSS punches may be significantly improved with a TiCN coating of $3000 \mathrm{HV}$, which protects the cutting edge against abrasive wear and has less affinity to pick-up than uncoated HSS, an observation confirmed independently by Wilson Tool Int., [76]. Good results have been obtained in coating of punches with $\mathrm{TiCN}$ for $\mathrm{Al}$ sheet perforation, increasing the tool life by a factor 10 due to reduced pick-up and increased wear resistance [75]. Oerlikon Balzers [84] reports that coating of punches with $\mathrm{AlCrN}$ gives three times longer tool life than TiN and TiCN.

\subsection{Structured workpiece surfaces}

The influence of workpiece surface topography on friction, lubrication and final surface quality in metal forming operations is well known and has been pointed out by many researchers, see for example $[15,20,23,52,178,211]$. This is especially the case when liquid lubricants are applied, where increased surface roughness facilitates the lubricant entrainment and surface transport. The potential of these mechanisms is, however, not fully utilized due to lack of understanding of the influence of individual parameters on the tribological system.

Engineering of surface topography for improved tribology obtained by deliberately introducing small cavities into the surface has been a subject for intense research and development since the 1990s, $[60,151,182,189]$. One of the most well-known examples is the surface structuring of blanks for sheet metal forming done by skin-pass rolling, the final rolling operation in the production of cold rolled steel sheet, which has quite different parameter settings than conventional sheet rolling due to small reduction (approximately 1\%), large contact length and high friction to ensure good replication of the roll surface texture, Finstermann et al. [55]. An analytical study of the roughness transfer and the influence of the rolling parameters is presented by Kijima and Bay, [106,107].

Structuring of the rolls for this final pass is done by shot blasting (SBT), electro discharge machining (EDT), [51], laser texturing (LT), [44] and electron beam texturing (EBT), [47,203]. Laser texturing has subsequently been abandoned due to poor performance. A more recent technique, which has given promising results, is based on the Electro Chromium Depositing technique (ECD), [86], which is described in Section 8.4. A 
comprehensive review regarding structured surface for sheet metal forming is given by Steinhoff, [191].

\subsubsection{Metal forming lubrication mechanisms applying structured surfaces}

The advantage of using structured sheet surfaces are due to the special lubrication mechanisms appearing when lubricant is entrapped in pockets in the surface, pressurized and subsequently extracted from the pockets. This mechanism was first proposed Mizuno and Okamoto [134], who named it MicroPlasto HydroDynamic Lubrication (MPHDL). In studies of plane strip drawing of aluminum provided with artificial lubricant pockets by local indentation with a Vickers pyramid Azushima et al. $[12,13]$ verified the proposed mechanism by direct observation of the tool/workpiece interface through a transparent die. They showed that lubricant escape from the pockets was influenced by the degree of reduction, drawing speed and lubricant viscosity. Although the liquid pressure in the pockets is smaller than the sealing pressure on the surrounding asperities in contact with the tool, the MPHDL mechanism is able to drag the lubricant out of the pockets implying good lubrication of the asperity contacts and low friction, Fig. 29.

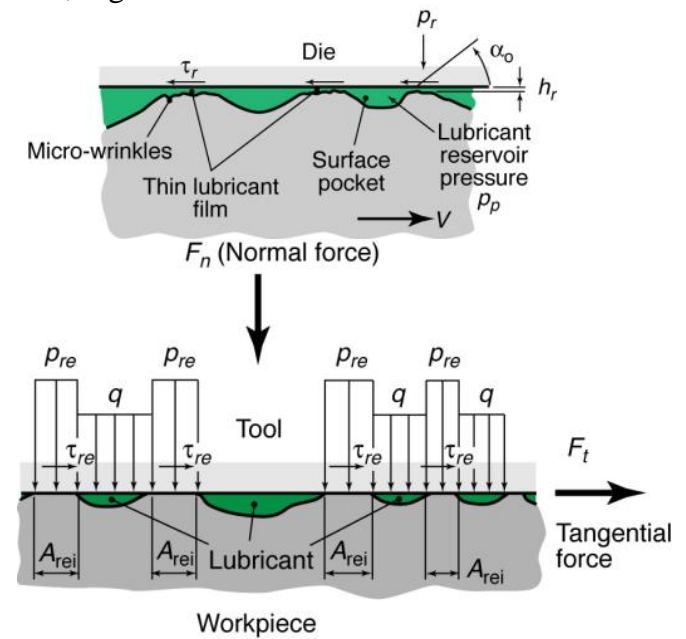

Fig. 29. Schematic outline of Micro-Plasto-Hydrodynamic Lubrication and local pressure distribution, [12].

Adopting the same direct observation technique as Azushima, Bay et al. [26,188] carried out a larger series of experiments with varying pocket geometry as well as lubricant viscosity, reduction and drawing speed. They established a theoretical model for the threshold reduction to onset of lubricant escape and showed that this was strongly dependent on the slope of the pocket wall, see Fig. 30 which verifies the model experimentally. The model gives an explanation to the poor performance of laser textured sheets, since the slope of such pockets is too large to ensure MPHDL, [191].

\subsubsection{Examples on application of structured workpiece surfaces}

With the improved understanding of MPHDL and the influence of pocket geometry, a number of researchers have focused on utilizing this knowledge. Groche et al. [67,72] have studied the performance of different surface texturing methods of cylindrical QSt36-3 billets in a two-step forward cold extrusion lubricated with a reduction oil Bechem KFP 10 as substitute to phosphate coating and soap lubrication. Structuring was done by the following methods: shot blasting with different sized steel balls as well as $\mathrm{Al}_{2} \mathrm{O}_{3}$ particles, laser structuring by a Nd:YAG

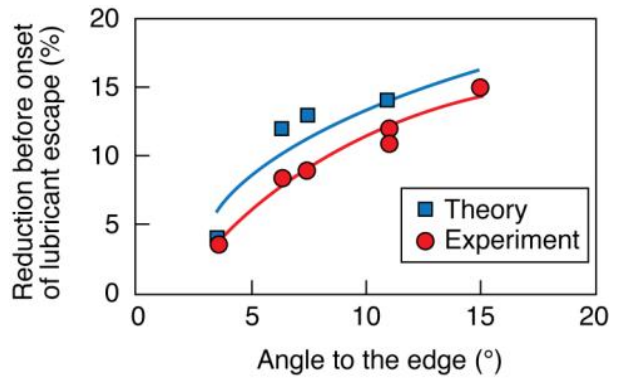

Fig. 30. Experimentally and theoretically determined reduction before onset of MPHDL as a function of the angle to the edge, [188].

laser with pulse and robot control and stochastic as well as deterministic electro-chemical etching. They found remarkable improvements as regards lowered friction force especially in the first operation, whereas the second extrusion step leveled the structured surfaces. The structuring by laser and deterministic electrochemical etching (using a pierced cover film on the wire surface) are very useful for obtaining a basic understanding of suitable surface structures but probably not feasible for industrial mass production.

Ngaile et al. [151] have pointed out the importance of low friction in tube hydroforming to avoid forming defects such as folding, bending, bursting, local thinning, surface damage or poor tolerances. They applied sandblasting to lower friction. Groche and Elsen [65] have also studied the influence of structured workpiece surfaces in hydromechanical forming of tubes. The tubes were made from seam-welded $\mathrm{AlMg}_{3} \mathrm{Mn}$ sheet metal. They compared an unstructured (mill finished) surface with surfaces structured by skinpass rolling of rolls textured by EDT as well as ECD and found substantial improvements, lowering the coefficient of friction by $50 \%$ using ECD structuring.

Nilsson et al. [153] have tested AISI 316 stainless steel sheet structured by electro-chemical etching. Testing of the sheet was done in a simulative strip reduction tester as well as in a laboratory deep drawing test lubricating with plain mineral oil with low viscosity, $10 \mathrm{cSt}$ at $40^{\circ} \mathrm{C}$. In the strip reduction test the as-received, cold rolled sheet surface resulted in immediate film breakdown, whereas the electro-chemically etched surface showed no sign of film breakdown at 20 and $30 \%$ reduction even after $300 \mathrm{~mm}$ sliding length. The deep drawing tests also showed significant improvements in lubrication performance when using structured blanks.

\subsection{Structured tool surfaces}

\subsubsection{Surface textured cold forging tools}

As discussed above, it is state-of-the-art in sheet metal forming to use special textured sheets providing a topography with lubricant pockets facilitating the forming process. Utilizing textured workpiece surfaces in bulk metal forming by shot blasting or other methods is less common due to two major disadvantages, [169]. First a time-consuming treatment of each single workpiece is necessary, and second, this effect works only in initial forming due to the large surface expansion and profound flattening of the surface asperities in bulk forming. This implies that later steps in multistage operations, which are common in bulk forming operations, are not supported. In contrast, the tool surface hardly changes even after prolonged use. Engel et. al. have utilized this effect in structuring of cold forging tools by laser ablation [163,169]. Using an excimer laser, local flat 
bottomed micropockets have been produced on the end surface of punches for backward can extrusions. Width and depth of the circular texture elements were set to $10 \mu \mathrm{m}$ and $1 \mu \mathrm{m}$ respectively see Fig. 31 . The punch was made in high speed steel and PVD coated with TiN. A liquid lubricant of kinematic viscosity $100 \mathrm{~m}^{2} / \mathrm{s}$ at $40^{\circ} \mathrm{C}$ was applied. Compared with the nontextured tool previously used the tool life was increased by approximately $50 \%$.

Popp and Engel explain the improved tool life by the pressurization of lubricant entrapped in the micro cavities of the tool surface, see Fig. 32. In [163] Otto et al. report the relationship between flank angle of the single texture element and relative tool life, see Fig. 33, in good accordance with the earlier mentioned importance of the slope of the pocket wall in textured sheet blanks, [188]. Adjustment of the flank angle is achieved by laser texturing with controlled defocusing. With this discovery new production tests resulted in significant extension of the punch life, [206].

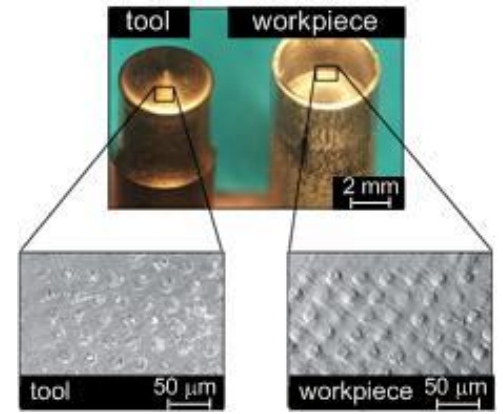

Fig. 31. Textured tool and workpiece in backward can extrusion.

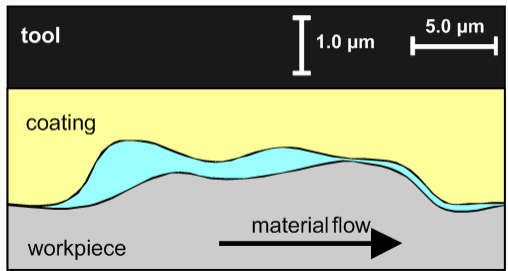

Fig. 32. Tool pocket profile and suggested lubrication mechanism [169].

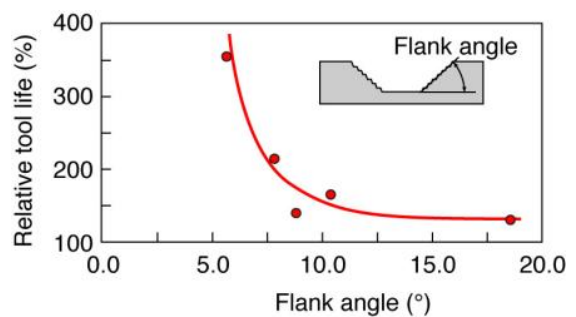

Fig. 33. Relation between flank angle of micropocket and tool life [163].

Davis et al. [43] have tested the influence of textured AISI D2 tool steel surface on friction in strip drawing of AHSS, DP600, at contact pressures ranging from 30-120 MPa. Texturing of $5 \%$ of the contact area was done with a picosecond laser producing $400 \times 100 \mu \mathrm{m}$ rectangular dimples in the tool surface of depth $25 \mu \mathrm{m}$. The coefficient of friction was reduced by up to $40 \%$, with the largest reduction appearing at the highest pressure and sliding speed.

\subsubsection{Alternative methods of texturing rolls for skinpass rolling}

As discussed in Section 8.3 the textured rolls applied for structuring of sheet by skinpass rolling are normally made by SBT, EDT or EBT. All these techniques present the problem of tool wear eventually deteriorating the surface texture of the rolls.

A rather new alternative is the Electro Chromium Depositing (EDC) mentioned in Section 8.3, [30,86,220]. Inserting the roll in a reactor containing a chrome-electrolyte, a coating with a topography consisting of small, hard, hemispherical particles is deposited on the roll surface by electrochemical plating. By skinpass rolling a rather uniform distribution of lubricant pockets is established, see Fig. 34.

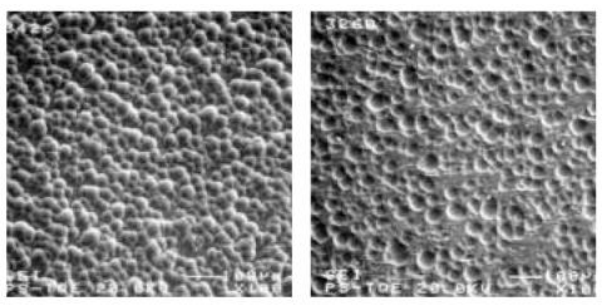

Fig. 34. Structure of a) roll surface and b) skinpass rolled sheet, [86]

Steinhoff et al. [184,190,191] have developed an alternative technique for structuring the rolls by local thermal implantation, see Fig. 35. After covering the surface of a cold work tool steel with a layer of hard ceramic particles, preferably of metal carbides, mixed with cleaning agents and binder, Thermal Implantation Zones (TIZ) are produced by local melting of the tool steel with a laser beam forming local hard spots. In contrast to the normal, stochastic tool wear of textured roll surfaces the surface of the TIZ tools possess a self-organizing property, where the wear is controlled. This is due to the fact that after an initial running-in period the softer matrix material will be in a slightly lower position than the TIZ and the surrounding heat affected zone of the tool material (HAZ). In this way the special surface structure is maintained, a feature which Steinhoff [191] suggests to apply for structured rolls for skinpass rolling.

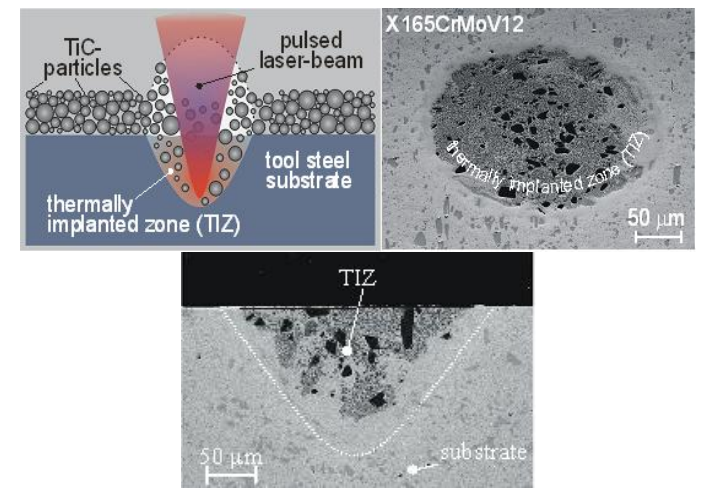

Fig. 35. Thermal implantation of TiC in cold work tool steel by laser beam, [190].

The technique has furthermore been applied to punches for cold forging, [190]. In such applications it is possible that the slightly lower tool steel matrix may ensure lubricant entrapment in a way similar to the one discussed in Section 8.1. Selecting lubricants with ability to react chemically with the tool steel matrix may further enhance the lubrication and as such be applied in severe cold forging operations as substitutes to zinc phosphate coating and soap lubrication. 


\section{Conclusions}

The increased focus on environmental issues in industrial production as well as on external environment has resulted in important developments of new, environmentally benign lubricants for metal forming. As regards cold forging new, single bath lubricant systems depositing a double layer of an inorganic salt and a wax on the slug surface have proven very efficient in substituting phosphate coating and soap lubrication. In warm and hot forging the black lubricants have been abandoned by many industries now using white lubricants on either polymer base, carvone base or liquid glass base. The huge amount of lubricant consumption in rolling has promoted the application of water based emulsions, which lubricate almost as well as the oil based and have better cooling efficiency.

In sheet metal forming pre-lubrication at the rolling mill with polymer coating is replacing in-process lubrication with mineral oils. Regarding more severe sheet forming of materials prone to galling a number of lubricant manufacturers have developed promising alternatives to chlorinated paraffin oils, such as mineral oils with $\mathrm{Ca}-, \mathrm{S}$ - and $\mathrm{P}$-additives and vegetable oils with fatty acid esters.

Generic measures towards introduction of new, environmentally benign lubricants include the development of anti-seizure tool materials. New multi-phase tool steel with finely distributed nitrides in a PM HSS matrix prevents seizure, probably due to a combination of anti-seizure properties of the nitrides and mechanical entrapment of lubricant in pockets in the tool surface. The idea of developing tribo-systems, where new lubricants can react chemically with the tool steel matrix material, seems promising and may be a route for replacement of chlorinated paraffin oils in severe stamping and punching operations of tribologcally demanding workpiece materials. An alternative solution is the introduction of anti-seizure tool coatings, where diamond coatings seem especially promising as regards the ultimate solution of metal forming without any lubrication. Further efforts on surface engineering to ensure entrapment and subsequent escape of lubricant by microhydrodynamic lubrication should be pursued in bulk as well as sheet forming.

\section{Acknowledgements}

The authors gratefully acknowledge contributions and assistance by T. Altan, Ohio State Univ., P. Bariani and S. Bruschi, Univ. Padova, W. Beekmans, The Netherlands, A. Bramley, Univ. Bath, D. Brans, Rhenus Lub., J. Cao, Northwestern Univ., L. Dubar, Univ. de Valenciennes et du Hainaut Cambrésis, U. Engel Univ. Erlangen, J. Holz and P. Zwez, ZWEZ-Chemie, H. Ike, RIKEN, Y.-T. Im, KAIST, J. Jeswiet, Queens Univ., Kingston, B. Kaftanoglu, Middle East Univ., Ankara, S. Kataoka, Shonan Inst. of Techn., K. Kitamura, Nagoya Inst. of Techn., F. Klocke, Aachen Univ., K. Kuzman, Univ. Ljubljana, M. Liewald, Univ. Stuttgart, P. Montmitonnet, CEMEF, K. Mori, Toyohashi Univ. of Techn., G. Ngaile, North Carolina State Univ., K. Osakada, Osaka Univ., K.P. Rao, City Univ. of Hongkong, O. Sandberg, Uddeholm Tooling, R. Shivpuri, Ohio State Univ., K. Steinhoff, Univ. Kassel, E. Suvanto, Pinifer, F. Vollertsen, BIAS.

\section{References}

[1] Andreasen, J.L., Bay, N., Andersen, M., Christensen, E., Bjerrum, N., 1997, Screening the performance of lubricants for ironing of stainless steel with a strip reduction test, Wear 207:1-5.

[2] Andreasen J.L., Bay N., De Chiffre L., 1998, Quantification of galling in sheet metal forming by surface topography characterisation, Int. Journal of Machine Tools and Manufacture 1998; 38(5-6):503-510.

[3] Andreasen, J.L., Olsson, D.D., Chodnikiewicz, K., Bay, N., 2006 Bending Under Tension Test with Direct Friction Measurement, IMechE Part B: J. Engineering Manufacture, 220:73-80.

[4] Anon, 1999, European Union Risk Assessment Report, alkanes, C1013, chloro (CAS No. 85535-84-8).

[5] Anon., 2002, Council regulations on existing substances (793/93/EEC). Risk assessment of alkanes, C14-17, chloro (CAS No. 85535-85-9).

[6] Anon., 2003, Development of replacements for phoscoating used in forging, extrusion and metal forming processes, National Center for Manufacturing Sciences, Ann Arbor, Michigan, USA.

[7] Anon., Replaceable Lubricants to Phosphate/Soap Treatment, Technical Bulletin of Daido Chemical Industry Co.

[8] Arentoft, M., Bay, N., Tang, T., Jensen, J.D., 2009, A New Lubricant Carrier for Metal Forming. Ann. CIRP, 58/1:243-246.

[9] Asaba, N., 2001, Non-conversion coating lubricants for cold forging, Anti-corrosion Management, 45-87:426-429. (In Japanese).

[10] Azushima, A.: 1988, Development of a simulation testing machine for evaluating the lubricity of lubricant in cold sheet rolling. Journal of the Iron and Steel Institute of Japan, 74/4: 696-702. (In Japanese).

[11] Azushima, A., Y., 1990, Evaluation system for using the newly developed oil in actual cold mill, Journal of the Iron and Steel Institute of Japan, 76/8:1270-1276. (In Japanese).

[12] Azushima, A., Uda, M. and Kudo, H., 1991, An Interpretation of the Speed Dependence of the Coefficient of Friction under the MicroPHL Condition in Sheet Drawing, Annals of the CIRP, 40/1, 227-230.

[13] Azushima, A., 1995, Direct Observation of Contact Behaviour to Interpret the Pressure Dependence of the Coefficient of Friction in Sheet Metal Forming, Annals of the CIRP, 44/1, 209-212.

[14] Azushima, A., Jimbo, Y., Setoguchi, S., 1998, "Effect of Roll Material on Lubrication Characteristics in Cold Sheet Rolling", Proceed. 7th Int. Conf. on Steel Rolling, Chiba, Japan, 446-451.

[15] Azushima, A., Miyamoto, J., Kudo, H., 1998, Effect of surface topography of work piece on pressure dependence of coefficient of friction in sheet metal forming, Annals of the CIRP 47/1:479-482.

[16] Azushima, A., Natsui, M., Inagaki, S., Sugai, T., 2000, Explanation of lubricant behavior by means of oil fim measurement on rolled sheet surface measured by fluorescence method, Journal of the Iron and Steel Institute of Japan, 86/11:755-760.

[17] Azushima, A., Xue, W.D., Yoshida, Y., 2007, Lubrication mechanism in hot rolling by newly developed simulation testing machine, Annals of CIRP, 56/1:297-300.

[18] Azushima, A, Xue, W.-D., Yoshida, Y., 2009, Influence of lubrican factors on coefficient of friction and clarification of lubrication mechanism in hot rolling, ISIJ, The Iron and Steel Institute of Japan, 49/6:868-873.

[19] Azushima, A., Nakata, Y., Toriumi, T., 2010, Prediction of effect of rolling speed on coefficient of friction in hot sheet rolling of steel using sliding-rolling simulator, Journal of Materials Processing Technology, 210/1:110-115.

[20] Balbach, R., Lange, K., 1987, Influence of various surface microstructures on the tribology in aluminium sheet metal forming, Annals of the CIRP, 36/1:181-184

[21] Bariani, P.F., Berti, G., Dal Negro, T., Masiero, S., 2002 Experimental evaluation and FE simulation of thermal conditions at tool surface during cooling and deformation phases in hot forging operations, Annals of CIRP, 51/1:219-222.

[22] Barus, C., 1893, Isothermals, isopiestics and isometrics relative to viscosity, American Journal of Science, 45:87-96.

[23] Bay, N. Wanheim, T., 1990, Contact phenomena under bulk plastic deformation conditions. Keynote paper at Symp. on Lubrication Mechanisms in Metal Forming. Proceed. 3rd Int. Conf. on Technol. of Plasticity, Kyoto, 4:1677-1691.

[24] Bay, N., 1994, The State of the Art in Cold Forging Lubrication, J. of Matls Process. Techn. 46:19-40. 
[25] Bay, N., Olsson, D.D., Andreasen, J.L., 2008, Lubricant Test Methods for Sheet Metal Forming. Tribology Int. 41/9:844-853.

[26] Bech, J., Bay, N., Eriksen, M., 1998, A study of mechanisms of liquid lubrication in metal forming. Annals of the CIRP, 47/1:221226.

[27] Becher, P., Emulsions: Theory and Practice, 2nd. ed., Reinhold Publishing, New York, 1965.

[28] Bertell, J.W., 1983, Synthetic hot forging lubricants and process. US Patent 4409113.

[29] Bjerrum, N.J., Christensen, E., Steenberg, T., 1996/2002, Method for electrochemical phosphating of metal surfaces, Danish patent, No. 0910/96/US patent, US 6,346,186 B1.

[30] Bolch, Th., Linde, R. Metzner, M., Müll, K., 2005, Innovative Oberflächenstrukturen durch elektrochemische Beschichtungsverfahren, Galvanotechnik, 103/9:2095-2100.

[31] Borsetto, F., Ghiotti, A., Bruschi, S., 2009, Investigation of the High Strength Steel Al-Si coating during hot stamping operations, Key Engineering Materials, 410-411:289-296.

[32] Borsetto, F., Ghiotti, A., Bruschi, S., Stoehr, T., Lechler, J., Merklein, M., 2010, Interlaboratory comparison of friction conditions in hot stamping operations, Key Engineering Materials, in press.

[33] Brans, D., 2009, Rhenus Lub GmbH \& Co KG, personal communication with N. Bay.

[34] Cann, P.M., Spikes, H.A., Hutchinson, J., 1996, The development of a spacer layer imaging method (SLIM) for mapping elastohydrodynamic contacts, Tribology Transactions, 39/4:915-921.

[35] Cassarini, S., Laugier, M., Montmitonnet, P., 2004, Modelling of metal forming lubrication by $\mathrm{o} / \mathrm{w}$ emulsions. In Bay, N. (Edtr.): Proceed. 2nd Int. Conf. Trib. Manufacturing, Nyborg, Denmark, 713720.

[36] Cavallo, J.L., Chang, D.L., Saleeb, F.Z., 1991, Formulation considerations in emulsion preparation and stability In Food Emulsions and Foams - Theory and Practice, AiChe Symp. Ser. V. 86:16-24.

[37] Cesur, H., Kaftanoglu, B., Kalkanli, A., Oral, B., 2008, Deposition of boron nitride coatings on steel substrates by RF magnetron sputtering, 7th ICMEN \& 3rd THE Coatings conferences, Kassandra, Greece.

[38] Cesur, H., Kaftanoglu, Ôzel, T., 2009, Machining performance of CBN coated cutting tool for die/Mold applications, 5th Int. Conf. and Exhib. on Design and Production of Machines and Dies/Molds, Kusadasi, Turkey.

[39] Chandrasekharan, S., Palaniswamy, H., Jain, N., Ngaile, G., Altan, T., 2005, Evaluation of stamping lubricants at various temperature levels using the ironing test, Int. J. Mach. Tools \& Manuf., 45: 379388.

[40] Chen, U.C., Liu, Y.S., Chang, C.C., Lin, J.F., 2002, The effect of the additive concentration in emulsions to the tribological behavior if a cold rolling tube under sliding contact, Tribology International, 35:309-325.

[41] Cortellaro, G., Bucci, E., Anelli, P., Yoshida, M., 2004, E-Phos® technology for wiredrawing, Wire Journal Int., 37/6, 67-69.

[42] Daouben E., Dubois A., Dubar M., Dubar L., Deltombe R., 2008, Effects of lubricant and lubrication parameters on friction during hot steel forging. In P. Boisse (Edtr.): Proceed. ESAFORM 2008, Lyon, France, Symposium No. 18 "Wear and friction in metal forming".

[43] Davis, T., Zhou, R., Pallav, K., Beltran, M., Cao, J., Ehmann, K., Wang, Q.J., Xia, C., Talwar, R., Lederich, R., 2008, Experimental friction study of micro-scale laser-textured surfaces, Proceed. Int. Workshop on Microfactories, Evanston, Il., USA, Oct., 31-35.

[44] Defourny, J.A., Leroy, V.M., Nilles, P.E., 1991, Update of developments in Lasertex technology, Iron and Steel Engineer, 68/8:39-45.

[45] Deltombe R., Dubar M., Dubois A., Dubar L., 2003, A New Methodology To Analyse Iron Fines During Steel Cold Rolling Processes. Wear, 254: 211-221.

[46] Dohda, K., Wang, Z., 1995, Investigation into relationship between friction behavior and plastic deformation using a newly devised rolling-type tribometer, Journal of Tribology, 117/3:529-533.

[47] Dolves, J., Hell, R., 1991, Electron beam texturing of rolls, Iron and Steel Engineer, 68/8:33-38.

[48] Dubar, L.,Bricout, J.P., Wierre, C., Meignan, P., 1998, New surface processes for cold forging of steels, Surf. and Coatings Techn., 102:159-167.
[49] Dubar M., Dubar L., Dubois A., 2005, Wear analysis of tools in cold forging: PVD versus CVD TiN coatings. Wear, 259:1109-1116.

[50] Dubar M., Huart S., Deltombe R., Dubois A., Dubar L., 2006, Cold rolling of galvanized strips: A new approach to the evaluation of zinc fines formation. Journal of Materials Processing Technology, 177:505-508.

[51] El-Menshawy, F., Snaith, B., 1991, Advances in electro-discharge texturing for cold mill work rolls, Iron and Steel Engineer, 68/8:5759.

[52] Emmens, W.C., 1988, The Influence of Surface Roughness on Friction. In: "Controlling Sheet Metal Forming Processes, Proceed. of the IDDRG Conf., ASM, Metals Park, Ohio, USA, 63-70.

[53] European Parliament, Council, 2006, REACH, EC Regulation No 1907/2006 of the European Parliament and of the Council.

[54] Fan, J., Spikes, H., 2007, New test for mild lubricated wear in rolling-sliding contacts, Tribology Transactions, 50:145-153.

[55] Finstermann, G., Nopp, G., Eisenköck, N., Keintzel, G., 2002, New Advances in Temper and Skin-Pass Rolling Technology, Proceed. of AISE (the Association of Iron and Steel Engineers) Annual Convention, Nashville, Tennesee, (CD-ROM).

[56] Friis, K.L., Nielsen, P.S., Bay, N., 2008, Testing and modelling of industrial tribo-systems for sheet metal forming. In: D.Y. Yang, Y.H Kim, C.H. Park (Edtrs.): Adv. Technol. of Plasticity 2008, Proceed. 9th ICTP, Gyeongju, Korea, 209-210.

[57] Fukuyama, S., Iwasaki, M., Nishimura, K., 1979, The effect of rolling condition on the heat-scratch at high speed cold rollinng of steel, Proceed. Japanese Spring Conf. for Techn. of Plasticity, 383386 ( In Japanese).

[58] Gariety, M., Ngaile, G., Altan, T., 2007, Evaluation of new cold forging lubricants without zinc phosphate precoat, Int. Journal of Mach. Tools \& Manuf., 47:673-681.

[59] Geiger, M., 1995, Towards clean forming technologies, Annals of the CIRP, 44/2:581-592.

[60] Geiger, M., Engel, U., Pfestorp, M., 1997, New developments for the quanlification of technical surfaces in forming processes, Annals of CIRP, 46/1:171-174.

[61] Geiger, Merklein, M., Hecht, J., 2006, Investigations on formability and tribology with regard to warm forming of magnesium sheets, Production Engineering, XIII/2:101-104.

[62] Geiger, Merklein, M., Lechler, J., 2008, Determination of tribological conditions within hot stamping, Production Engineering, 2/3:269-276.

[63] Groche, P., Kappes, B., Dünkel, V., Mauer, G., 2001, Signification of tribology bench tests in cold bulk forming, Proceed. WTC, Vienna.

[64] Groche, P., Nitzsche, G., Callies, T., 2004, Mechanisms in abrasive behavior of hot-dip zinc coatings on deep drawing steel sheets, Production Engn. Research and Developm., XII/2/2:61-64.

[65] Groche, P., Elsen, A., 2007, Werkstatttechnik online, 97/10:821-817.

[66] Groche, P., Koehler, M., 2008, Final report of AIF-project 14511. (In German).

[67] Groche, P., Stahlmann, J., Hartel, J., Köhler, M., 2009, Hydrodynamic effects of macroscopic deterministic surface structures in cold forging processes, Tribology Int., 42/8:1173-1179.

[68] Hansen, P.H., Bay, N., 1990, Prediction of wear distribution in forming tools, Proceed. 9th Int. Conf. on Experimental Mechanics, Copenhagen, Denmark, 1:19-30.

[69] Heikkilä, I, 2004, Tool material aspects in forming of stainless steel Proceed. Int. Conf. on Recent Advances in Manufacturing \& Use of Tools a\& Dies in Stamping of Steel Sheet, Olofström, Sweden, 139149.

[70] Hibi, T., 1993, Aqueous high molecular weight polymer lubricant for hot forging, Technical Review by Forging Technology Institute of Japan, 18-53:41-48. (In Japanese).

[71] Hirai, K., 1984, Lubricants for Deformation Processes, J. of JSTP 25-285:878-885. (in Japanese).

[72] Hoffmeister, H., Schoppe, F., Ostrowski, J., Köhler, M., Groche, P., 2009, Cold forging without zinc-phosphate layers - economical and ecological potential, Proceed. 24. Jahrestreffen der Kaltmassivumformer, VDI. (In German).

[73] Horita, T., 2001, Non-chlorinated lubricants for cold forging, Technical Review by Forging Technology Institute of Japan, 2687:59-62. (In Japanese).

[74] Hosford, W. F. and Duncan, J. L., 1994, The aluminum beverage can, Scientific American, 271:48-53. 
[75] http://archive.metalformingmagazine.com/2003/10/Punching Aluminium.pdf

[76] http://archive.metalformingmagazine.com/2003/08/Wilson.pdf

[77] http://irmco.com

[78] http://www.cdc.gov/niosh/98-102.html

[79] http://www.coldforming.chemetall.com

[80] http://www.env.go.jp/en/laws/policy/basic/index.html

[81] http://www.env.go.jp/en/laws/recycle/01.pdf

[82] http://www.man.dtu.dk/ ENLUB: Development of new environmentally acceptable lubricants, tribological tests amd models for European sheet forming industry. EU GROWTH project Contract No. GRD1-2001-40717

[83] http://www.pinifer.com

[84] Oerlikon Balzers; http://www.oerlikon.com

[85] http://www.rhenuslu.de

[86] http://www.salzgitterflachstahl.de/en/Produkte /kaltfein_oberflaechenveredelte_produkte/pretex/

[87] http://www.trumpf.de/3.punching-tools_coating_v1.html

[88] ICFG Doc. 8/91, 1991, Lubrication Aspects in Cold Forging of Carbon Steels and Low Alloy Steels. The International Cold Forging Group.

[89] ICFG Doc. 10/95, 1996, Lubrication Aspects in Cold Forging of Aluminium and Aluminium Alloys. The International Cold Forging Group, 1995. Publ. in WIRE 1:1-12 (supplement of WIRE)

[90] Ike, H., 2004, Report on Metal Forming Tribology Research in Japan with Special Focus on Environmental Aspects. In: Bay, N. (Edtr.): Proceed. Int. Conf. on Tribology in Manuf. Process., ICTMP2, Nyborg, Denmark, 29-38.

[91] Imazu, K., Kobayashi, T., 1996, Studies of the stretch draw forming conditions of laminated steel, In Altan, T.(Edtr.): Advanced Technology of Plasticity. Proc. 5th ICTP, Ohio, USA, 727-730.

[92] Imazu, K., 2001, Development of metal can with low environemnetal load, J. JSTP, 42/484:416-420. (In Japanese).

[93] Imazu, K., 2005, Dry forming method using polyester film laminated plate as pre-coating material, 2005, J. JSTP, 46/528:19-23. (In Japanese).

[94] Ishii, M., Mishima, K., 1984, Two-fluid model and hydrodynamic constitutive relations, Nuclear Engineering and Design, 82:107-126.

[95] Jaworski, J.A., Schmid, S.R., 1999, Survivability of laminated polymer lubricant films in ironing, Tribology Transactions, 42:32-38.

[96] Jaworski, J.A., Schmid, S.R., Wang, J.E., 1999, An experimental investigation of the formability and friction characteristics of tin coated and polymer laminated steels, J. Manufacturing Sci. and Eng., 121: 232-237.

[97] Jimbo, Y., Hiroshige, T., Azushima, A., 1998, Measurement of critical interfacial temperature by means of the thermoelectric method in cold sheet rolling, Journal of Iron and Steel Inst. Jpn, 84/6:423-428 (In Japanese).

[98] Jimbo, Y., Azushima, A., 2001, Effect of carbide properties of roll materials on lubricity in cold sheet rolling of low-carbon steel, Int. Journal of Machine Tools \& Manufacture, 41:347-360.

[99] Jimbo, Y., Azushima, A., 2001, Lubrication characteristsics of physical vapor deposition TiN-coated roll for high productivity in cold rolling of low-carbon steel sheet, Wear, 249:415-421.

[100] Kaftanoglu, B., 2009, Middle East Technical University, Ankara, personal communication with N. Bay.

[101] Kashimura, N., Takeuchi, M., Oda, F., Kawahara, F., Ojima, H., Tomono, M., 2000, Development of Environmentally Friendly Lubricant for Cold Forging with High Performance and Simple Treatment, J. of the JSTP, 41-469:109-114. (In Japanese).

[102] Kataoka, S., Murakawa, M., Aizawa, T., Ike, H., 2004, Tribology of deep-drawing of various metal sheets with use of ceramic tools, Surface Coating Techn., 177-178:582-590.

[103] Kataoka, S., Motoi, A., Tamaoki, K., Murakawa, M., Noguchi, H., Kihara, J., 2005, Improvement in DLC thin film adhesion and its application to deep-drawing, J. JSTP, 46/532:412-416 (In Japanese).

[104] Kataoka, S., 2009, Shonan Inst. Techn., Fujisawa, personal communication with N. Bay.

[105] Kawabe, T., 1993, Lubricants for hot forging, Technical Review by Forging Technology Institute of Japan, 18-53:13-15. (In Japanese).

[106] Kijima, H., Bay, N., 2008, Skin-pass rolling I - Studies on roughness transfer and elongation under pure normal loading, Int. J. Mach. Tools and Manuf. 48:1313-1317.

[107] Kijima, H., Bay, N., 2008, Skin-pass rolling II - Studies of roughness transfer under combined normal and tangential loading, Int. J. Mach.
Tools and Manuf. 48:1308-1312

[108] Kim, H., Sung, J.H., Sivakumar, R., Altan, T., 2007, Evaluation of stamping lubricants using the deep drawing test, Journal of Machine Tools \& Manufacture, 47/14:2120-2132.

[109] Kim, H., Han, S., Yan, Q., Altan, T., 2008, Evaluation of tool materials, coatings and lubricants in forming galvanized advanced high strength steels (AHSS), Annals of the CIRP, Manufacturing Technology, 57:299-304.

[110] Kim, H., Sung, J., Goodwin, F.E., Altan, T., 2008, Investigation of galling in forming galvanized advanced high strength steels (AHSS) using the twist compression test (TCT), J. Materials Process. Techn., 205:459-468.

[111] Kim, H., Altan,. T., Yan, Q., 2009, Evaluation of stamping lubricants in forming advanced high strength steels (AHSS) using deep drawing and ironing tests, J. Materials Process. Techn., 209:4122-4133.

[112] Kimura, Y., Okada, K., 1987, Film thickness at elastohydrodynamic conjunctions lubricated with oil-in-water emulsions, Proceed. IMechE, C176:85-90.

[113] Kimura, Y., Okada, K., 1989, Lubricating properties of oil-in-water emulsions, Tribology Transactions, 32:523-532.

[114] Klocke, F., Massmann, M., Gerschwiler, K., 2005, Combination of PVD tool coatings and bidegradable lubricants in metal forming and machining, Wear:259:1197-1206.

[115] Klocke, F., Massmann, M., Bobzin, K., Lugscheider, E., Bagcivan, N., 2006, Carbon based tool coatings as an approach for environmentally friendly metal forming processes, Wear, 260/3:287295

[116] Klocke, F., Kuwer, C., Wear reduction in the sheet-metal forming of AISI 304, 2007, In Azushima, A.(Edtr.): Proceed. Int. Conf. on Tribology in Manuf. Process., Yokohama, Japan, 207-212.

[117] Klocke, F., Massmann, T., Zeppenfeld, C., Schmidt, R.-A., Schulz, J., Mumme, F., 2008, Fineblanking with Non-chlorinated lubricants, Tribologie und Schmierungstechnik, 55/4:33-38.

[118] Kobatashi, N., Moriyama, A., Yoshida, M., 2005, Electrolytical Phosphating Process for Stel Wire Drawing. Nihon Parkerizing, Technical report No. 17.

[119] Komatsuzaki, S., Uematsu, T., Narahara, T., 1998, Effects of extreme pressure additives in forward extrusion, J. of JSTP, 29330:748-754. (In Japanese).

[120] Komatsuzaki, S., 1986, Extreme pressure additives for cold forging lubricant, J. of Japan Soc. of Lubrication Engineers, 31-6:381-386. (In Japanese).

[121] Lazzarotto L., Dubar L., Dubois A., Ravassard P., Oudin J., 1998 Three selection criteria for the cold metal forming lubricating oils containing extreme pressure agents. Journal of Material Processing Technology, 80-81:245-250.

[122] Lechler, J., Merklein, M., 2008, Investigations on forming limits witihn hot stamping. Proceed. $1^{\text {st }}$ Int. Conf. Hot Sheet Metal Forming of High-Performance Steel, 55-62.

[123] Lockwood, F., Bridger, K., Tudros, M., 1984, Interactions between rolling oil emulsions and aluminum alloy surfaces, ASLE Transactions, 27:203-206.

[124] Louaisil K., Dubar M., Deltombe R., Dubois A., Dubar L., 2009 Analysis of interface temperature, forward slip and lubricant influence on friction and wear in cold rolling. Wear, 266/1-2:119 128

[125] Lugscheider, E., Bobzin, K., Colmenares, C., Klocke, F., Massmann, T., 2004, Development and optimization of a superlattice TiHfCrN coating for cold metal forming applications, Surface Coating Techn. 177-178:612-622.

[126] Mahanti, S., Bhatta, A.K., Biswas, R.N., Bhatia, J., Singh, S.N., 1990, Development of a meta-stable semi-synthetic lubricant for cold rolling of steel, J. Synthetic Lubrication, 6:285-298.

[127] Maratray, F., Usseglio-Nanot, R., 1975, Factors affecting the structure of chromium and chromium-molybdenum white irons, Climax Molybdenum, S.A., 10.

[128] Matsumoto, R., Osakada, K., 2002, Lubrication and friction of magnsium alloys in warm forging, Annals of the CIRP, 51/1: 223226.

[129] Matsumoto, R., Kawashima, H., Osakada, K., 2007, J. of Solid Mechanics and Materials Engineering, 1/4: 397-405.

[130] Meguro, Y., 1993, Non-graphite lubricants for hot forging, Technical Review by Forging Technology Institute of Japan, 18-53:16-22. (In Japanese)

[131] Meiler, M., Pfestorf, M., Geiger, M., Merklein, M., 2003, The use of 
dry film lubricants in aluminium sheet metal forming, Wear of materials, 255:1455-1462

[132] Meiler, M., Pfestorf, M., Merklein, M., Geiger, M., 2004 Tribological properties of dry film lubricants in aluminium sheet metal forming, In Bay, N. (Edtr.): Proceed. 2nd Int. Conf. on Tribology in Manuf. Process., ICTMP2, Nyborg, Denmark, 489-500.

[133] Meiler, M., Jaschke, H., 2005, Lubrication of aluminium sheet metal within automotive industry, Advanced Materials Research, 6-8:551558

[134] Mizuno, T. and Okamoto, M.,1982, Effects of Lubricant Viscosity at Pressure and Sliding Velocity on Lubricating Conditions in the Compression-Friction Test on Sheet Metals, Trans. ASME, J. of Lubr. Technol., 104:53-59.

[135] Montmitonnet, P., Stephany, A., Cassarini, S., Ponthot, J.P., Laugier, M., Legrand, N., 2007, Modelling of metal forming lubrication by $\mathrm{o} / \mathrm{w}$ emulsions. In Azushima, A. (Edtr.): Proceed. Int. Conf. Trib. Manuf. Process., Yokohama, 85-90.

[136] Mori, K., Murao, T., Harada, Y., 2003, Multi-stage cold deep drawing of long, pure titanium cups using coloured sheets for prevention of seizure, Annals of the CIRP, 52/1:237-240.

[137] Morishita, K., 2001, Trends of Environmentally Friendly Lubricants for Cold Forging. , Technical Review by Forging Technology Institute of Japan, 26-87:12-18. (In Japanese).

[138] Morishita, M., 2007, Tribology in Manufacturing Processes of Automobiles at Toyota. In Azushima, A. (Edtr.): Proceed. 3rd Int. Conf. on Tribology in Manufacturing Processes, ICTMP3, Yokohama, Japan, 1-9.

[139] Moroi, T., Koide, Y., Katoh, M., 2002, Report of Aichi Steel Co., 201:23-25. (In Japanese).

[140] Mould, R., Silver, H.B., Syrett, R., 1973, Investigations of the activity of cutting oil additives III. Oils containing both organochlorine and organosulphur compounds, Wear, 26:27-37.

[141] Murakawa, M., Koga, N., Kumagai, T., 1995, Deep-drawing of aluminium sheets without lubricant by use of Diamond-Like Carbon coated dies, Surface and Coating Techn.,76-77/2:553-558.

[142] Murakawa, M., Koga, N., Watanabe, S., Takeuchi, S., 1998, Tribological behavior of amorphous hard carbon films against zincplated steel sheets, Surface and Coating Techn., 108-109:425-430.

[143] Murakawa, M., Takeuchi, S., 2003, Evaluation of tribological properties of DLC films used in sheet metal forming of aluminium sheet, Surface and Coating Techn., 163-164:561-565.

[144] Nakahara, T., Makino, T., Kyogoku, K., 1988, Observations of liquid droplet behavior and oil film formation in o/w type emulsion lubrication, Journal of Tribology, 110:348-353.

[145] Nakahara, T., Shiokawa, S., Kyoguku, K., 1990, "Phase inversion region in $\mathrm{o} / \mathrm{w}$ emulsion lubrication," Japanese Journal of Tribology, 35:1435-1436.

[146] Nakamura, T., 1993, Counter measures for seizure phenomena in deformation processes, J. of JSTP, 34-393:1082-1090. (In Japanese).

[147] Nakamura, T., Ishibashi, I., 2004, Environmentally Friendly Lubrication System for Forging, English translation of Report from JSTP's Sub-Committee on Process-Tribology.

[148] Nakamura, T., Sumioka, Y., Sagisaka, Y., Ishibashi, I., Sekizawa, M., 2008, Lubrication Performance of Environmentally Friendly Lubricants for Forging, 1st report. Proceed. 59th Japanese Joint Conference for the Technology of Plasticity, 579-580.

[149] Nakamura, T., Sumioka,, Y., Sakoda, K., Miyano, S., Ishiizumi, Y., Ishibashi, I., Sekizawa, M., 2008, Lubrication Performance of Environmentally Friendly Lubricants for Forging, 2nd report. Proceed. of the 59th Japanese Joint Conference for the Technology of Plasticity, 333-334.

[150] Nakamura, T., Tanaka, S., Hayakawa, K., Tsunekawa, T., 2008, Tribo-characteristics of titanium sheet in iterative processes of sheet metal forming, In Yang, D.Y., Kim, Y.H., Park, C.H. (Edtrs.): Advamced Technology of Plasticity, Proceed. $9^{\text {th }}$ ICTP, 2077-2082.

[151] Ngaile, G., Gariety M., Altan T., 2006, Enhancing tribological conditions in tube hydroforming by using textured tubes, Journal of Tribology, 128:674-676.

[152] Ngaile,G.,Cochran, J., Stark, D., 2007, Formulation of polymerbased lubricant for metal forming, Proc. IMechE, Part B, J. Engineering Manufacture, 221:559-568.

[153] Nilsson, M.S., Olsson, D.D., Petrushina, I., Andreasen, J.L., Bay, N., Christensen, E., Bjerrum, N.J., 2010, Int. J. Surface Science and Engineering, 4/1:68-79.

[154] Nittel, K.D., 2008, Neue Beschichtungen und Trends beim
Kaltfliesspressen und Kaltstauchen. Proceed. 23th Jahrestreffung der Kaltmassivumformer, Düsseldorf, VDI. (In German).

[155] Ohmori, T., Kitamura, N., Danno, A., Kawamura, M., 1991, A Cold Forging Oil Containing Phosphorus Type EP Additives, Tribology Transactions, 34-3:458-464.

[156] Ohmori, T., Kitamura, N., Danno, A., Kawamura, M., 1991, Lubricity of lubricants added phosphate extreme pressure additives for cold forging, Tribologist, 36-6:452-458. (In Japanese).

[157] Olesen, P.T., Steenberg, T., Christensen, E., Bjerrum, N.J., 1998, Electrolytic Depositions of Amorphous and Crystalline $\mathrm{Zn} / \mathrm{Ca}$ Phosphates on Stainless Steel, J. Materials Science, 33:3059-3063.

[158] Olsson, D.D., Bay, N., Andreasen, J.L., 2002, Analysis of pick-up development in punching, Annals of the CIRP 51/1:185-190.

[159] Olsson, D.D., Bay, N., Andreasen, J.L., 2002, Lubricant test for punching and blanking, In: M. Kiuchi(Edtr.): Advanced Technology of Plasticity. Proc. 7th ICTP, Yokohama, Japan, 757-762. Shorter version publ. in JSTP Journal, Special Issue, 2003-04, 44/507:356358.

[160] Olsson, D.D., Bay, N., Andreasen, J.L., 2005, Direct friction measurement in draw bead testing, In P. Bariani (Edtr.): Advanced Technology of Plasticity. Proceed. 8th ICTP, Verona, 633-634.

[161] Olsson, D.D., Bay, N., Andreasen, J.L., 2010, A quantitative lubricant test for deep drawing. Int. J. Surface Science and Engineering, 4/1:2-12.

[162] Osakada, K., Matsumoto, R., 2000, Fundamental study of dry metal forming with coated tools, Annals of the CIRP, 49/1:161164.

[163] Otto, A., Weidel, S., Engel, U., Geiger, M., 2007, Laser in metal forming - benefits for tribology. In Bach, F.-W., Bouzakis, K.-D., Denkena, B., Geiger, M. (Edtrs.): Proceed. 6th Int. Conf. THE Coatings, Hannover, Germany, 13-22.

[164] Petek, A. Podgornik, B., Kuzman, K., Cekada, M., Waldhauser, W., Vizintin, J., Stefan, J., 2008, The analysis of complex tribological system of single point incremental sheet metal forming - SPIF, Strojniski vestnik - J. of Mech. Engn., 54/4:266-273.

[165] Pfestorf, M. Müller, M., 2001, Application of aluminium in automotive structure and hang on parts, Proceed. Materials Week, Int. Congr. on Advanced Materials, their Processes and Applications, Munich, Germany.

[166] Pfestorf, M., Meiler, M., Merklein, M., Geiger, M., 2004, New Tribological Aspects of Dry Film Lubricated Aluminium Sheet Metal. In: Geiger, M.; Bouzakis, K.-D.; Denkena, B.; Toenshoff, H.K.; Bach, F.-W.; Popp, U. (Edtrs.): Proceed. 4th Int. Conf. THE Coatings in Manufacturing Engineering, Bamberg, Meisenbach, $497-$ 506

[167] Podgornik, B., Hogmark, S, Pezdirnik, J., 2004, Comparison between different test methods for evaluation of galling properties of surface engineered tool surfaces, Wear, 257:843-851.

[168] Podgornik, B., Hogmark, S., Sandberg, O., 2004, Influence of surface roughness and coating type on the galling properties of coated forming tool steel, Surface and Coating Techn. 184:338-348.

[169] Popp, U., Engel, U., 2006, Microtexturing of cold-forging tools influence on tool life, 2006, Proceed. IMechE, Part B, J. Engineering Manufacture, 220:27-33.

[170] Rao, K.P., Xie, C.L., 2006, A comparative study on the performance of boric acid with several conventional lubricants in metal forming,Tribology Int., 39:663-668.

[171] Renaudin, J.F., Batit, G., Thore, Y., Felder, E., 1983, A Way to Build a Computer Program for Forecasting the Abrasive Wear of Hot Forging Dies, 11th Int. Drop Forging Conf., Köln.

[172] Sakaguchi, Y, Wilson, W.R.D., 1984, EHD analysis of the behavior of emulsions at the inlet of roll bites, Proceed. 5th Conf. Plastic Working, Japan Society for Technology of Plasticity, Tokyo.

[173] Sandberg, O., Bustad, P.-Å., Carlsson, B., Fällström, M., Johansson, T., 2004, Characterisation of tool wear in stamping of EHS and UHS steel sheets. Proceed. Int. Conf. on Recent Advances in Manufacturing \& Use of Tools a\& Dies in Stamping of Steel Sheet, Olofström, Sweden, 151-169.

[174] Sandberg, O., 2008, Advanced low-friction tool steel for metal processing: properties and industrial experiences, Int. J. Microstructure and Materials Properties, 3/2-3:391-400.

[175] Sandberg, O., Högman, B., Johansson, B., Thuvander, A., 2008, New tool comcept for stamping of HSS and AHSS sheet, Proceed. Int. Conf. on Deep Drawing, IDDRG, Olofström, Sweden, 591-602.

[176] Sato, T., Besshi, T., 1998, Anti-galling evaluation in aluminium sheet forming, J. Materials Processing Techn., 83:185-191. 
[177] Sato, T., Besshi, T., Tsutsui, T., Morimoto, T., 2000, Anti-galling property of a diamond-like carbon coated tool in aluminium sheet forming, J. of Materials Processing Techn., 104:21-24.

[178] Schey, J.A., 1983, Tribology in Metalworking. Friction, Lubrication and Wear, ASM, Metals Park, Ohio.

[179] Schmid, S.R., Wilson, W.R.D., 1995, Lubrication of aluminum rolling by oil-in-water emulsions, Tribology Transactions, 38:452 458.

[180] Schmid, S.R., Wilson, W.R.D., 1996, Lubrication mechanisms for oil-in-water emulsions", Lubrication Engineering, 52:168-175.

[181] Schmid, S.R., Yang, H., Reich, R., Kasun, T., 2004, "Developments in emulsion lubrication", In Bay, N. (Edtr.): Proceed. 2nd Int. Conf. on Tribology in Manuf. Process., ICTMP2, Nyborg, Denmark, 509519.

[182] Schmoeckel, D., Prier, M., Staeves, J., 1997, Topography deformation of sheet metal during the forming process and its influence on friction, Annals of CIRP, 43/1: 175-178.

[183] Schmoeckel, D., Rupp, M., 1997, More environment friendly cold massiv forming - production of steel without zinc phosphate layer (In German). Proceed. Neuere Entwicklundeg der Massivumformung, Stuttgart, 183-200.

[184] Schuleit, N., Fletcher, D., Kapoor, A., Steinhoff, K., 2000, New laser surface treatment for improving mechanical and tribological properties of forming tools, Proceed. 1st Europäischer Kongress für Wärmebehandlung und mechanishe Oberflächenbehandlung "ATTT2000", Metz, France, 29-36.

[185] Sellés-Cantó, M., Schmid, S.R., and Segui, V.J., 2008, Ironability of a three-layered polymer coated steel - Part 1: experimental investigation, J. Materials Processing Technology, 202:7-14.

[186] Shida, S., 2002, Environmentally Friendly Lubricants for Cold Forging. Proceed. 215th Symp. of JSTP, 215:33-39 (In Japanese).

[187] Shimizu, A., 2008, Lubrication Technology for Cold Forming in the 21st Century. Nihon Parkerizing Technical Report No. 20.

[188] Soerensen, C.G., Andreasen, J.L., Bech, J., Bay, N., Engel, U., Neudecker, T., 1999, A basic study of the influence of surface topography on mechanisms of liquid lubrication in metal forming, Annals of the CIRP, 48/1/:203-208.

[189] Staeves, J., 1998, Beurteilung der Topografie von Blechen in Hinblick auf die Reibung bei der Umformung, Darmstadt, Technische Universität, PtU, PhD thesis, Shaker Verlag (in German).

[190] Steinhoff, K., 2004, Self-organizing Tool Surfaces for Metalworking Processes. In: Bay, N. (Edtr.): Proceed. 2nd Int. Conf. on Tribology in Manufacturing Processes, Nyborg, Denmark, 605-612.

[191] Steinhoff, K., 2008, Neues zur Strukturierung von Feinblechoberflächen. In: Steinhoff, K.; Kopp, R. (Edtrs.): Umformtechnik im Spannungsfeld zwischen Plastomechanik und Werkstofftechnik. Bad Harzburg (D): Grips Media GmbH, 239-260. (In German).

[192] Takaishi K., Iwaki, T., Kondo, T., Sasaki, K., Abe, Y., 2002, Extension of blanking die life by surface coatings. In Azushima, A (Edtr.): Advanced Technology of Plasticity, Proceed. of the 7th ICTP, Yokohama, Japan, 2:1657-1662.

[193] Takeuchi, M., Ikesue, F., Kashimura, N., 1999, Development of Environmentally Friendly Lubricant with High Performance and Simple Treatment for Cold Forging. In: Geiger, M. (Edtr.): Advanced Technology of Plasticity. Proc. 6th ICTP, Nürnberg, 383389.

[194] Tamaoki, K., Kataoka, S., Minamoto, K., 2007, Dry deep-drawing with use of electroconductive ceramic tools, In: Bay, N. (Edtr.): Proceed. Int. Conf. on Tribology in Manuf. Process., Nyborg, Denmark, 175-179.

[195] Tamaoki, K., Kataoka, S., Kanda, K., Tanako, S., Teranish, T., 2008, Study of deep drawing using diamond coated tools, Journal of Material Testing Research Assoc. of Japan, 53/4:247-253. (In Japanese).

[196] Tang, P.T., Arentoft, M., Bay, N., Borrild, M., Mizushima, I., Jensen, J.D., Paldan, N.A., 2008, A microporous layer for lowering friction in metal forming processes", Patent PCT/DK2008/000233.

[197] Tolazzi, M., Meiler, M., Merklein, M., 2005, Tribological investigations on coated steel sheets using the dry film lubricant Drylube E1, Advanced Materials Research, 6-8:565-572.

[198] Totten, G.E., Wedeven, L.D., Anderson, M., Dickey, J.R., 2001, Bench Testing of Industrial Fluid Lubrication and Wear Properties Used in Machinery Applications, American Society for Testing and Materials, STP1404.
[199] Tsuda, S., Yoshihara, S., Kataoka, S., 2009, Formability of AZ31 magnesium alloy sheet in dry press forming using diamond-coated dies, Proceed. ASME IMECE2009, Lake Buena Vista, Florida, USA, 1-6

[200] Uno, A., Shida, S., Tomono, M., Shimizu, T., Sano, T., 2002 Development of Waste Free Water-system Lubricant for Cold Forging. In Kiuchi, M. (Edtr.): Advanced Technology of Plasticity. Proc. 7th ICTP, Yokohama, 1669-1673.

[201] Utsunomiya, H., Kawajiri, S., Takahira, N., Miyamoto, J., Sakai, T., Tanaka, T., 2007, Porosification of Steel Surface - New Lubrication System for Cold Forging In: A. Azushima (Edtr.): Proceed. 3rd Int. Conf. on Tribology in Manuf. Process., ICTMP3. Yokohama, 63-72.

[202] van der Schaft, J.C., 1993, Eindrapport droogstampen en milieuvriendelijke smeermiddelen, Philips report PHR-58-93-02-006. (In Dutch).

[203] Vermeulen, M., Scheers, J., 2001, Micro-hydrodynamic effects in EBT textured steel sheet, Int. J. of Machine Tools \& Manuf., 41/13:1941-1951.

[204] Vucich, M.G., Vitellis, M.X., 1976, Emulsion control and oil recovery on the lubricating system of double-reduction mills, Iron and Steel Eng., 29-38.

[205] Wagner, S., Kleinert, H., Zimmermann, R., 2002 Trockenschmierstoffe für die Blechumformung, In Proceed. Int Conf. "Neuere Entwicklungen in der Blechumformung", Stuttgart, Germany, 459-480. (In German).

[206] Wagner, K., Völk, R., Engel, U., 2008, J. Materials Process. Techn., 201:2-8

[207] Wang, Z., Dohda, K., Jeong, Y.-H., 2003, Lubricity of volatile lubricants in sheet metal rolling, Journal of Materials Processing Technology, 140/1-3:548-554

[208] Wibom, O., 1998, Tribology in cold forging of stainless steel, PhDthesis, Technical Univ. of Denmark, (In Danish).

[209] Wilson, W.R.D., Walowit, J.A., 1972, An isothermal lubrication theory for strip rolling with front and back tension, Proceed. of Trib. Conv. 1971, Proc IMechE:164-172.

[210] Wilson, W.R.D., Sakaguchi, Y., Schmid, S.R., 1994, A mixed flow model for lubrication with emulsions, Tribology Transactions, 37:543-551.

[211] Wilson, W.R.D., 1995, Low-Speed Mixed Lubrication of MetalForming Processes, Annals of the CIRP, 44/1:205-208

[212] Yamamoto, N., 2002, Tribology in Forging, Tribologist 47-6:451 456. (In Japanese).

[213] Yanagida, A., Azushima, A., 2009, Evaluation of coefficients of friction in hot stamping by hot flat drawing test, Annals of the CIRP 58/1:247-250

[214] Yang, H., Schmid, S.R., Reich, R., Kasun, T., 2006, Direct observations of emulsion flow in EHL contact, Journal of Tribology, 128:619-623.

[215] Yokota, H., Endo, K., and Shibata, J., 1994, "Metal working fluids", Journal of the Japanese Society of Tribologists, 39:892.

[216] Yokoyama, T, 2001, Recent new lubricants for forging, Technical Review by Forging Technology Institute of Japan, 26-87:48-52. (In Japanese).

[217] Yoshida, M., 2001, Characteristics and application of recent lubricants for cold forging, Technical Review by Forging Technology Institute of Japan, 26-87:53-58. (In Japanese).

[218] Yoshida, M., Imai, Y., Yamaguchi, H., Nagata, S., 2003, Nihon Parkerizing, Technical Report No. 15.

[219] Zajec, B., Podgornik, B., Bay, N., Vizintin, J., 2007, Influence of hard coatings on process of stamping. In Azushima, A. (Edtr.): Proceed. 3rd Int. Conf. on Tribology in Manufacturing Processes, ICTMP3, Yokohama, Japan, 181-184.

[220] Zimnik, W.,Ritterbach, B., Müll, K., 1998, Pretex, Ein neues Verfahren zur Erzeugung texturierter Feinbleche für höchste Ansprüche, Stahl und Eisen, 118/3:75-80.

[221] Zwez, P., Holz, J., 2009, ZWEZ-Chemie, personal communication with N. Bay. 